\title{
Analysis of Dynamic Response and Fatigue Life of Masonry Pagoda under the Influence of Train Vibration
}

\author{
Qian Xia $\mathbb{D}^{1},{ }^{1}$ Jin Zhao, ${ }^{1,2}$ Defa Wang, ${ }^{1}$ and Yiqing $\mathrm{Li}^{2,3}$ \\ ${ }^{1}$ School of Civil Engineering and Architecture, Xi'an University of Technology, Xi'an 710048, China \\ ${ }^{2}$ Shaanxi JDWG Quality Testing Technology Co., Ltd., Xi'an 710018, China \\ ${ }^{3} X i$ 'an University of Architecture and Technology, Faculty of Civil Engineering, Xi'an 710018, China \\ Correspondence should be addressed to Qian Xia; ice69pipiniu@163.com
}

Received 18 February 2020; Revised 21 August 2020; Accepted 25 September 2020; Published 19 October 2020

Academic Editor: Jinyang Xu

Copyright (C) 2020 Qian Xia et al. This is an open access article distributed under the Creative Commons Attribution License, which permits unrestricted use, distribution, and reproduction in any medium, provided the original work is properly cited.

Taking Liangxiang Pagoda built in Liao Dynasty in Beijing as the research object, the vibration responses of the pagoda in the eastwest direction and south-north direction under the action of trains on the Beijing-Guangzhou Railway Line and microseism were tested. On this basis, a numerical model was established by using ANSYS to further calculate the dynamic response of the pagoda, and the safety and integrity of the pagoda were evaluated based on existing standards. Cumulative fatigue damage theory was introduced to predict the remaining fatigue life of Liangxiang Pagoda. The following conclusions have been drawn: in the two directions mentioned above, the natural vibration frequencies of the pagoda of the first three orders are similar; the $1^{\text {st }}$-order vibration modes in the plane are bending, and the vibration modes of the $2^{\text {nd }}$ and $3^{\text {rd }}$ orders are shear-bending; under the action of trains, the peak vibration value of Liangxiang Pagoda at the position that bears the maximum load is $0.053 \mathrm{~mm} / \mathrm{s}$, which has a little impact on the safety and integrity of the pagoda; under the combined action of gravity and trains, the remaining fatigue life of Liangxiang Pagoda is $5.26 \times 10^{7}$ times. The research method used in this paper can provide data and scientific support for the protection of historical buildings, as well as the basis for the follow-up research of the studied ancient pagoda.

\section{Introduction}

With the explosion of urban motor vehicles and the formation of the rail transit network, the environment for ancient buildings in urban areas is becoming worse. Ancient building is a special architecture which not only indicates "ancient" regarding the construction time but also is endowed with historical and cultural properties in the long development process of history. Ancient building, being irreparable for its historical particularity, has certain defects and damage inside it. Under the action of static load, the damage has little impact on the safety and integrity of the structure; however, under the continuous action of microvibration caused by traffic, the damage accumulates over time, thereby giving rise to cracks that will lead to structure failure $[1,2]$.

In terms of the study of ancient architectures, Hinzen [3], through field test, analyzed the influence of vibration caused by the Cologne subway on Cologne Cathedral and studied the effect of vibration reduction measures. Schillemans [4] studied the impact of the Antwerp double railway tunnel on the vibration of buildings along the railway and determined the corresponding vibration reduction measures that would not damage the buildings. Javad Sadeghi and Esmaeili [5], through theoretical analysis and experimental study, investigated the vibration damage of historical buildings caused by the operation of underground railways and established a finite element model to predict the safe distance between subway lines and historical buildings. In addition, Meng et al. [6,7] and Ma et al. [8,9] studied the dynamic response of the bell tower under the influences of Metro Line 2 and Line 6. Yun [10], through numerical simulation, analyzed the influences of the buried depth of metro track, vibration source distance, and metro velocity on the vibration response of Dayan Tower. In terms of fatigue life research, Poveda et al. [11] and Tarifa et al. [12] 
used numerical analysis and a full-scale model to analyze the fatigue life of Japanese slab ballastless track. Zeng et al. [13] established a twin-block ballastless track concrete model of fatigue life prediction. Li and Xing [14] used a numerical analysis method to calculate the fatigue life of each member of a bridge under fatigue load and then studied the fatigue life of the bridge. Peng et al. [15] and Yan [16] calculated the fatigue life of the pavement structure under different working conditions through field measurement and finite element numerical model.

The existing researches on ancient buildings are mainly focused on the prediction of microvibration, and most studies of the fatigue life are carried out on architectures such as railway, bridges, and tunnels whose structural materials are mainly concrete and steel. No effective systematic research has been conducted on theoretical issues such as fatigue life prediction of ancient buildings under the microvibration of trains. Therefore, this paper, based on the field vibration test of Liangxiang Pagoda, studies the dynamic characteristics of and the influence of train vibration on the pagoda. This paper proposes for the first time to study ancient architectures from the perspective of fatigue life and by combining theoretical calculation with fatigue analysis software Fe-safe to analyze the fatigue life of ancient masonry architectures scientifically and systematically. The method proposed in this paper can provide data and scientific supports for the protection of historical architectures, as well as a data basis for the follow-up research of the studied ancient pagoda.

\section{General Situation of Experiment}

2.1. Introduction to Liangxiang Pagoda and Its Environmental Conditions. Liangxiang Pagoda which is also known as Haotian Pagoda or Treasure Pagoda, as shown in Figure 1, is located in the Fangshan District of Beijing. Built over one thousand years ago in the Liao Dynasty, it is a five-layer central-pillar pagoda with double ambulatories and has an octagonal plane. The stairs are between the central column of the tower and the inner wall (inner corridor), rotating up towards; there is an outer corridor between the inner wall and the outer wall. The pagoda is $45.852 \mathrm{~m}$ in height and large at the bottom and small on the top (The main structure dimensions of the Pagoda are shown in Table 1). With abundant relives, the pagoda is of great ornamental and research values. The pagoda was listed as a cultural relic protection site by the Beijing Municipal Government in 1987 and was rated as a key cultural relic site under national protection in May 2013.

Liangxiang Pagoda is adjacent to the Beijing-Guangzhou Railway Line (see Figure 2). Located in the northwest of Liangxiang Pagoda, Beijing-Guangzhou Line, which runs on an ordinary railway track, is one of the busiest railway transport arteries that connect the northern and southern cities of China, so it carries lots of trains every day both for passenger and freight transport.

2.2. Measuring Equipment. The dynamic test on Liangxiang Pagoda was performed with an INV3018CT24 24-bit highprecision data acquisition instrument. This instrument

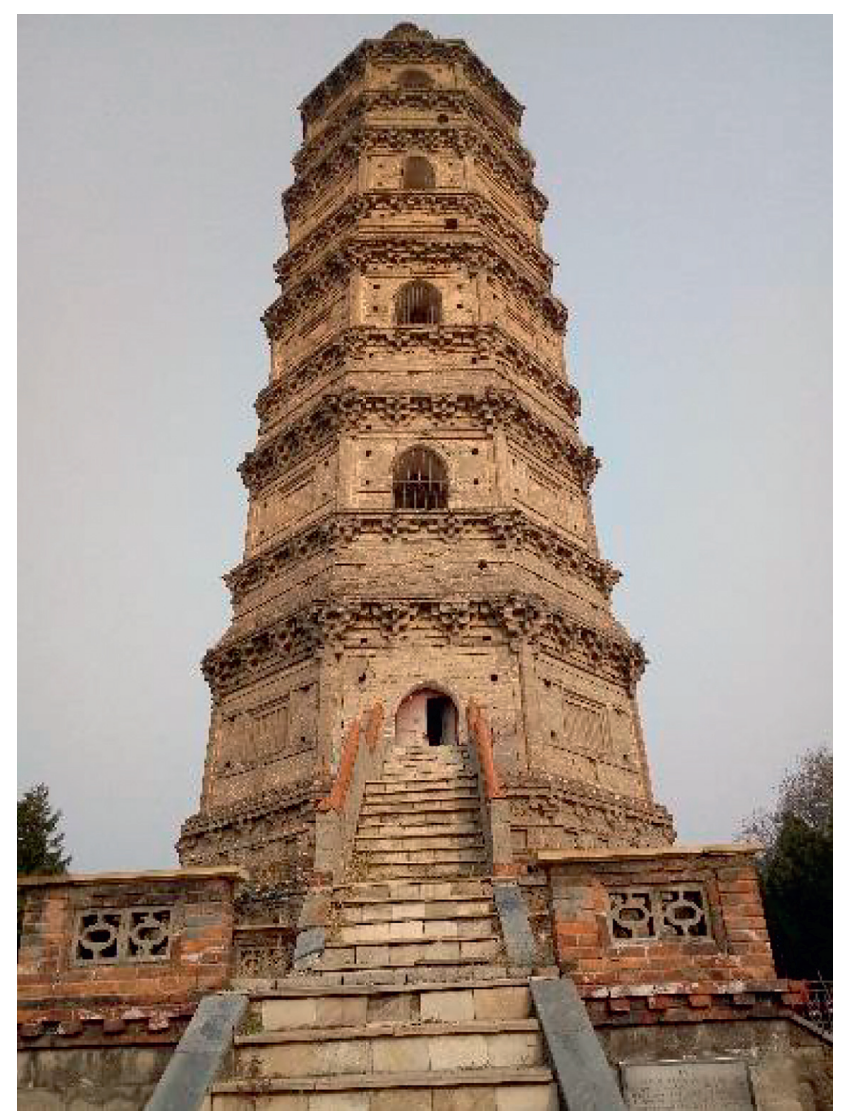

Figure 1: Liangxiang Pagoda.

adopts the latest DSP and FP0A technologies and thus supports multichannel parallel operation. The highest sampling frequency is $102.4 \mathrm{kHz}$; the indicating value error of frequency and the resolution error are below $0.01 \%$; the indicating value error of frequency spectrum amplitude is smaller than $1 \%$.

A $941 \mathrm{~B}$ ultra-low frequency vibration meter which is equipped with four gears of speed (namely, acceleration, low speed, medium speed, and high speed) is used for velocity measurement. The gear of low speed is used in this test; the sensitivity is about $24 \mathrm{mV} /(\mathrm{mm} / \mathrm{s})$ and the maximum measurement range is $0.125 \mathrm{~m} / \mathrm{s}$. The acceleration is measured with an LC0130 IC piezoelectric acceleration sensor whose sensitivity is about $37 \mathrm{~V} / \mathrm{g}$, the measurement range is $3 \mathrm{~g}$, and the frequency range is $0.1 \sim 2000 \mathrm{~Hz}$.

2.3. Sampling Frequency. To ensure the accuracy of signal acquisition, certain rules should be followed in sampling, quantization, time-domain truncation, etc. Besides, some techniques are employed to ensure the authenticity of the signals obtained. Therefore, the sampling frequency $f_{s}$ should be $f_{s} \geq 2 f_{m}$, where $f_{m}$ is the highest frequency of the analysis signal. In practice, the sampling frequency is usually 3 4 times the upper limit of analysis [17]. Liangxiang $\mathrm{Pa}-$ goda is adjacent to Beijing-Guangzhou Railway Line, and the main response frequency band of the ancient pagoda caused by road traffic vibration is below $20 \mathrm{~Hz}[18,19]$. Thus, to 
TABle 1: Dimensions of Liangxiang Pagoda (m).

\begin{tabular}{|c|c|c|c|c|c|c|c|c|}
\hline Floor & $\begin{array}{c}\text { Story } \\
\text { height }\end{array}$ & $\begin{array}{l}\text { Length of } \\
\text { outer wall }\end{array}$ & $\begin{array}{l}\text { Length of } \\
\text { inner wall }\end{array}$ & $\begin{array}{l}\text { Thickness of } \\
\text { outer wall }\end{array}$ & $\begin{array}{l}\text { Thickness of } \\
\text { inner wall }\end{array}$ & $\begin{array}{c}\text { Tower } \\
\text { column }\end{array}$ & Gate arch & $\begin{array}{c}\text { Thickness of } \\
\text { floor slab }\end{array}$ \\
\hline Tower spire & 6.588 & - & - & - & - & - & - & - \\
\hline 5 & 5.742 & 4.056 & 2.143 & 1.386 & - & $2.4 \times 2.4$ & $1.45 \times 2.28$ & 1.91 \\
\hline 4 & 5.807 & 4.362 & 2.602 & 1.478 & 1.108 & $2.4 \times 2.4$ & $1.57 \times 2.54$ & 1.94 \\
\hline 3 & 6.521 & 4.668 & 2.602 & 1.755 & 1.108 & $2.4 \times 2.4$ & $1.61 \times 2.65$ & 2.17 \\
\hline 2 & 7.203 & 4.974 & 2.755 & 1.940 & 1.108 & $2.4 \times 2.4$ & $1.68 \times 2.84$ & 2.40 \\
\hline 1 & 7.619 & 5.281 & 2.755 & 2.032 & 1.108 & $2.4 \times 2.4$ & $1.80 \times 3.28$ & 2.54 \\
\hline $\begin{array}{l}\text { Foundation } \\
\text { support }\end{array}$ & 6.372 & 6 & - & - & - & - & - & - \\
\hline
\end{tabular}

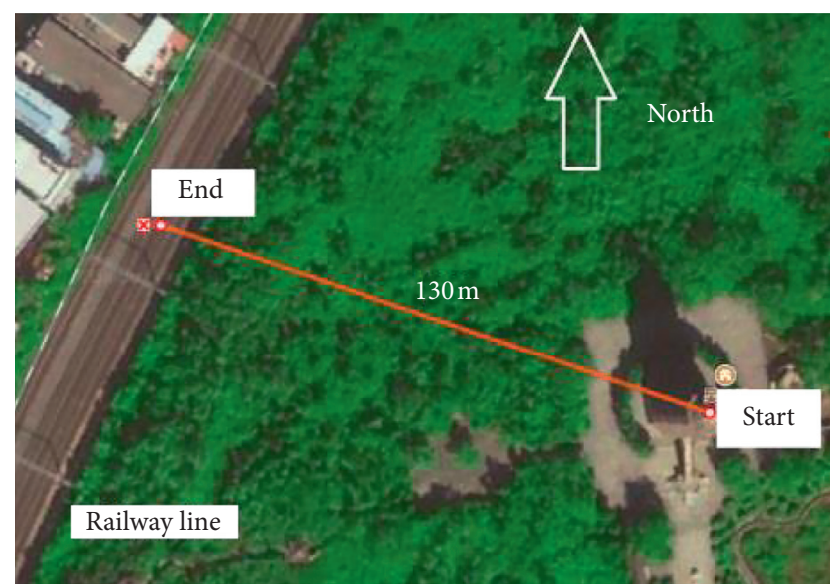

Figure 2: Horizontal distance between Liangxiang Pagoda and Beijing-Guangzhou Railway Line.

collect the train vibration signals, the sampling frequency of this test was set to $128 \mathrm{~Hz}$.

2.4. Layout of Measuring Points. Measuring points were arranged in the same positions on the first floor to the fifth floor to collect the velocity signals under the action of microseism and trains. Ideally, the sensors should be placed at the stiffness center of the structure and avoid special locations like stairs to guarantee that the horizontal vibration signals are not interfered by torsional vibration. However, since the center of the pagoda is occupied by central columns and the inner corridors are staircases, sensors were placed on the floor of the outer corridor of each layer. Two measuring points were arranged on each floor, so there are 10 measuring points in total, denoted as P1-P10. A horizontal sensor was placed at each measuring point, and vibration velocity signals were collected in two horizontal directions; that is, east-west direction and south-north direction. Specifically, measuring points $\mathrm{P} 1-\mathrm{P} 5$ and $\mathrm{P} 6-\mathrm{P} 10$ were used to collect the signals in the east-west direction and southnorth direction, respectively.

A measuring point, denoted as $\mathrm{P} 0$, was arranged on the ground of the pagoda. Meanwhile, one vertical sensor and two horizontal sensors were placed at this point to collect the acceleration signals in vertical, east-west, and north-south directions under the action of trains. The layout of measuring points is shown in Figure 3; in the plane of the first floor (Figure 3(b)), the shaded areas represent walls.

In order to minimize the errors caused by the test and obtain a more accurate dynamic response value of the structure, the synchronous test method should be employed. As the vibration pickup is limited in number, the sensors at P0 kept collecting signals continuously; and the signals of the $1^{\text {st }} \sim 5^{\text {th }}$ floor in the east-west direction were collected firstly and those in the southnorth direction were collected subsequently. The dynamic testing site at Liangxiang Pagoda is shown in Figure 4. The pagoda is located in the Haotian Park, which was off limits to visitors during the test, so the test environment was excellent and the test was free from the interference of other vibration signals.

\section{Experimental Result Analysis}

\subsection{Analysis on the Dynamic Characteristics of Liangxiang Pagoda under Microseism}

3.1.1. Analysis on Natural Frequency of Vibration. According to the random vibration theory, the natural vibration frequency of the ancient pagoda is identified, as shown in the following equation [20]:

$$
|H(\omega)|^{2}=\frac{G_{y y}(\omega)}{G_{f f}(\omega)},
$$

where $G_{y y}(\omega)$ is the autopower spectrum of the vibration response $y(t)$ of structure and $G_{f f}(\omega)$ is the autopower of input source's exciting force $f(t)$.

While testing the dynamic characteristics of the ancient pagoda in a vibration environment, the input excitation signals cannot be measured accurately as there are vibration signals such as environmental vibration and wind vibration in the input signals. For that reason, the input excitation signal is roughly regarded as white noise with limited bandwidth; then the power spectrum of the input excitation signal is a constant Const; thus, there exists

$$
|H(\omega)|^{2}=\frac{G_{y y}(\omega)}{G_{f f}(\omega)}=\frac{G_{y y}(\omega)}{\text { Const }} .
$$

Obviously, the natural vibration frequency can be identified through the autopower spectrum of the vibration response of the ancient pagoda. Owing to the influence of measurement noise during the field test, the peak value of the autopower spectrum of the pagoda is not necessarily the 


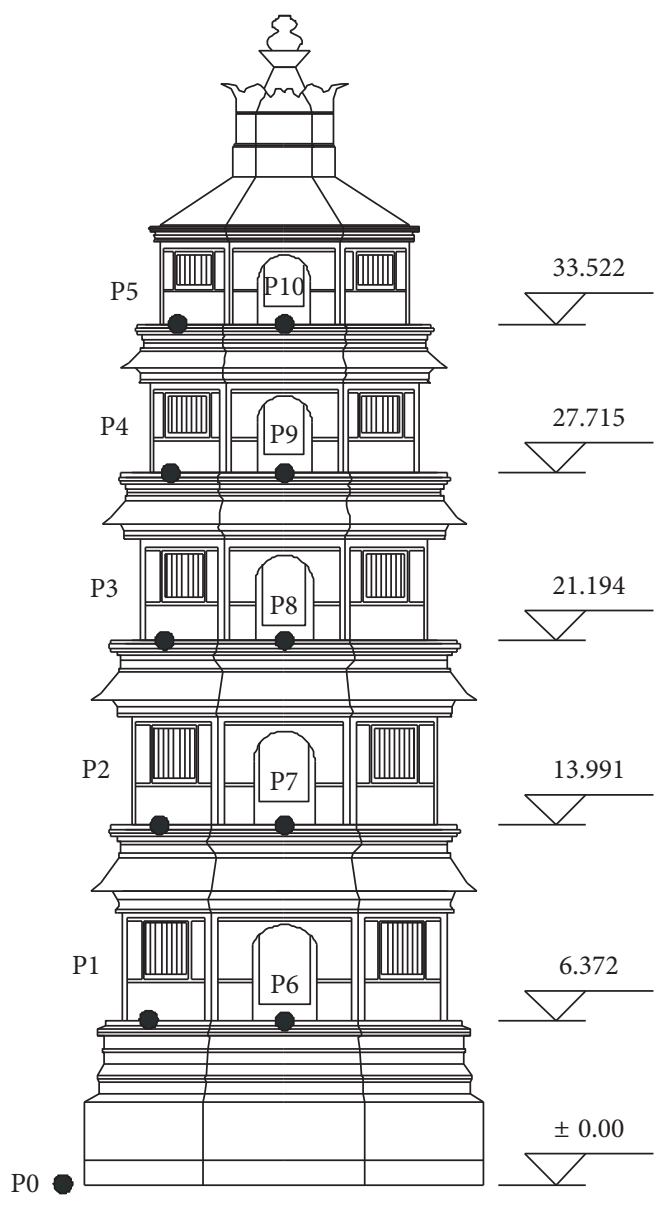

(a)

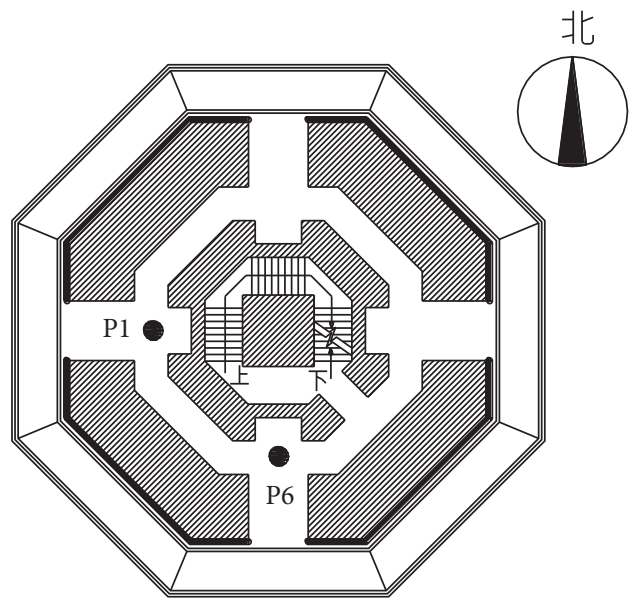

(b)

Figure 3: Layout of measuring points. (a) Front view. (b) Plan of the first floor.

modal frequency. Therefore, the following principles are used for modal frequency identification [21]:

(1) The peak autopower spectrums of velocity response of the measuring points appear at the same frequency

(2) The coherence function values among the measuring points at the common peak frequency are relatively large

(3) At the common peak frequency, the phase between the measuring points is close to $0^{\circ}$ or $\pm 180^{\circ}$; that is, the measuring points show synclastic or anticlastic relationships

Based on the above approaches, MATLAB is used to analyze the autopower spectrum of each measuring point (Figures 5 and 6), cross-power spectrum, and phase spectrum (Figures 7 and 8). Due to space limitation, only the cross-power spectrum and phase spectrum curves of the measuring points of the $1^{\text {st }}$ and the $3^{\text {rd }}$ floor in the east-west direction and south-north direction are presented. As can be known from the figures, except for the ground measuring points, the frequencies corresponding to the peak values of the autopower spectrum and cross-power spectrum response curves of each measuring point are close to each other. And the phase at the peak value is close to $0^{\circ}$ or $\pm 180^{\circ}$, which is the natural vibration frequency of each order of the ancient pagoda. After calculating the average of the frequencies of the same order corresponding to each point, the natural vibration frequency of the first three orders of the ancient pagoda in both directions can be obtained, as shown in Table 2.

As can be seen from Table 2, the frequencies of the first two orders are equal in the two directions, while those of the third order differ slightly. The major reason is that the pagoda plane is octagonal, and the stiffness differs insignificantly in the two directions; accordingly, the natural vibration frequencies in the two directions are close.

3.1.2. Vibration Mode Analysis. According to the dynamic test results under random ground excitation, the ancient pagoda is equivalent to a multidegree of freedom system. Then, the ratio of the vibration mode coordinates corresponding to the $i$-th order frequency meets [22]

$$
\frac{\varphi_{1 i}}{\varphi_{2 i}}=\frac{S_{12}\left(\omega_{i}\right)}{S_{22}\left(\omega_{i}\right)}
$$

where $\varphi_{1 i}$ and $\varphi_{2 i}$ are the $i$-th order vibration mode coordinates of $\mathrm{P} 1$ and $\mathrm{P} 2$, respectively; $S_{12}\left(\omega_{i}\right)$ is the peak value of 


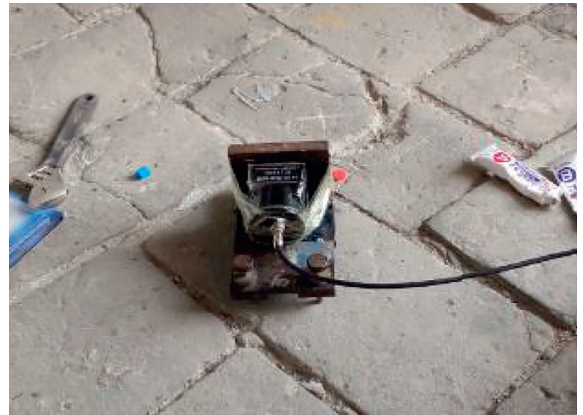

(a)

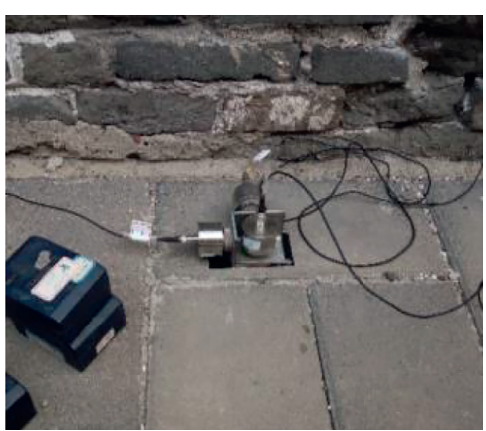

(b)

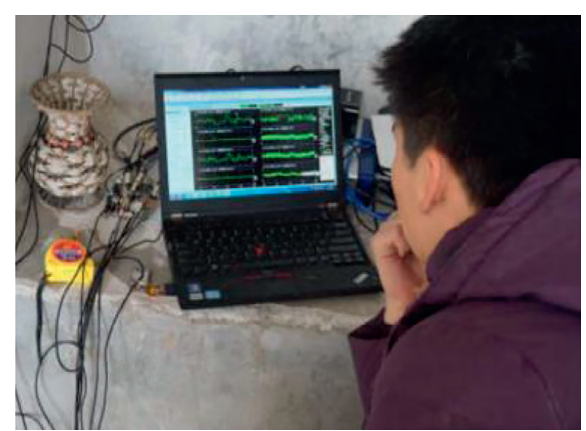

(c)

Figure 4: Dynamic test site at Liangxiang Pagoda. (a) Speed sensor arrangement. (b) Acceleration sensor arrangement. (c) Data acquisition equipment debugging.

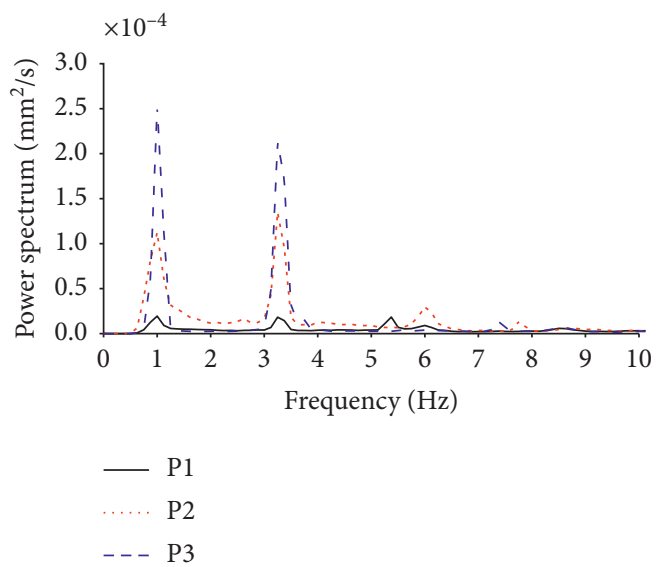

(a)

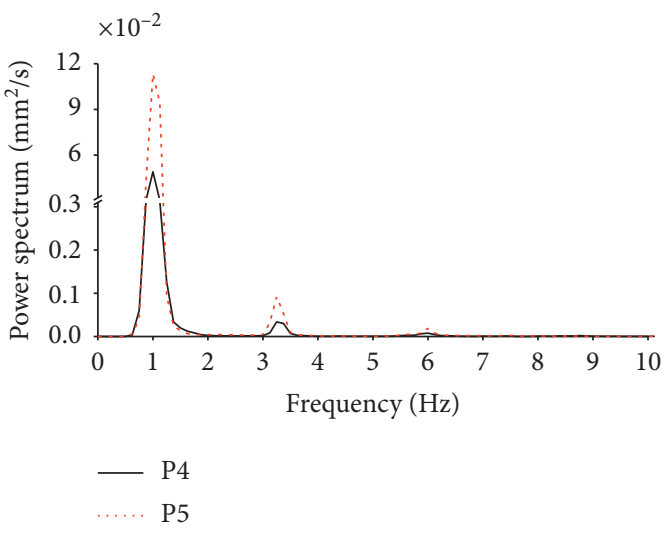

(b)

FIGURE 5: The autopower spectrums of measuring points in the east-west direction. (a) The autopower spectrum of measuring points on floors 1-3. (b) The autopower spectrum of measuring points on floors 4-5.

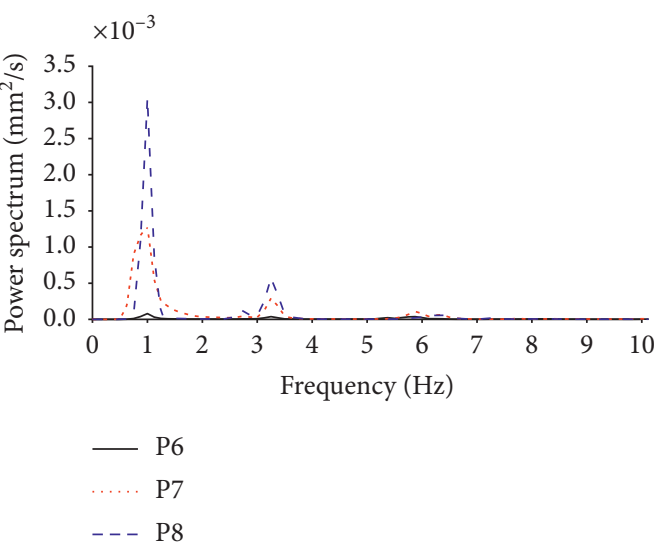

(a)

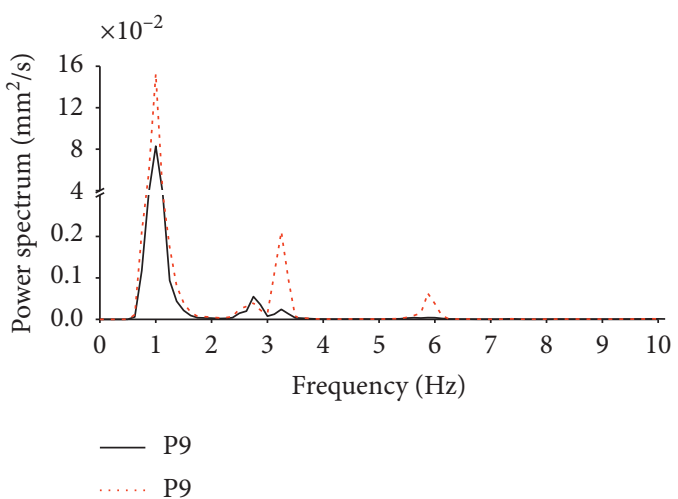

(b)

FIgURE 6: The autopower spectrums of measuring points in the south-north direction. (a) The autopower spectrum of measuring points on floors 1-3. (b) The autopower spectrum of measuring points on floors 4-5.

cross-power spectrum of P1 and P2; and $S_{22}\left(\omega_{i}\right)$ is the peak value of autopower spectrum of $\mathrm{P} 2$.

Based on the power spectrum analysis on each measuring point's signals, the vibration mode coordinates of the first three orders of the pagoda are obtained through equation (3), according to which the vibration mode diagrams are plotted, as shown in Figure 9. It can be seen that the $1^{\text {st }}$ order vibration modes in the plane in the two 


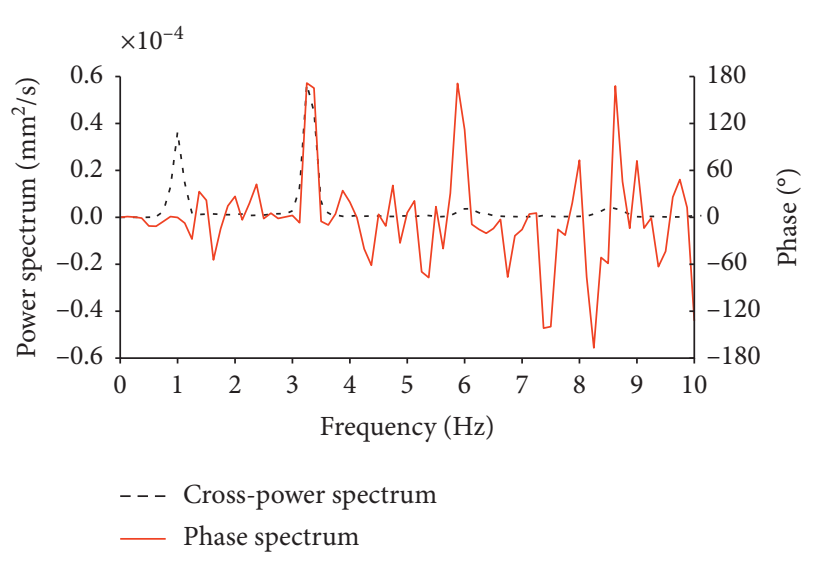

FIgURE 7: The cross-power spectrums and phase spectrums of P1 and P3 in the east-west direction.

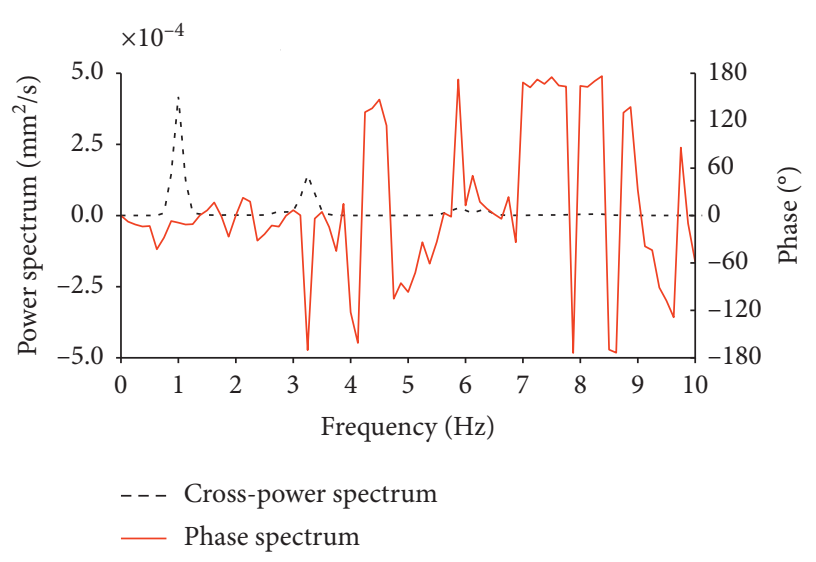

Figure 8: The cross-power spectrums and phase spectrums of P6 and $\mathrm{P} 8$ in the south-north direction.

TABLE 2: Test results of natural vibration frequency.

\begin{tabular}{lccc}
\hline & $\begin{array}{c}\text { The } 1^{\text {st }} \\
(\mathrm{Hz})\end{array}$ & $\begin{array}{c}\text { The } 2^{\text {nd }} \text { order } \\
(\mathrm{Hz})\end{array}$ & $\begin{array}{c}\text { The } 3^{\text {rd }} \text { order } \\
(\mathrm{Hz})\end{array}$ \\
\hline $\begin{array}{l}\text { East-west } \\
\text { direction }\end{array}$ & 1 & 3.25 & 6 \\
$\begin{array}{l}\text { North-south } \\
\text { direction }\end{array}$ & 1 & 3.25 & 5.875 \\
\hline
\end{tabular}

directions are bending; the $2^{\text {nd }}$ and $3^{\text {rd }}$ vibration modes are shear-bending, and only the vibration mode curves are slightly different.

\subsection{Dynamic Response Analysis of Liangxiang Pagoda under} the Influence of Trains. The type and number of trains collected in the field test are given in Table 3.

The average of the horizontal peak velocities of Liangxiang Pagoda under the action of each train presented in Table 3 is illustrated in Figure 10, where the peak value is the average of the maximum peak values in positive and negative directions. It can be known from Figure 10 that, under the excitation of trains, the vibration velocities of the floors of Liangxiang Pagoda in the east-west and south-north directions present different rules with the increase of floor layers; specifically, the peak velocity in east-west direction is more complex; that is, it shows a large change in the fourth floor and a slightly decreasing-increasing-decreasing tend from the first floor to the top floor while the vibration velocity in south-north direction is relatively regular and shows a slow-growing trend in general.

Limited by field testing conditions, the vibration response at the roof panel of the fifth floor that bears the largest load cannot be measured. Obviously, it is not accurate to determine whether the vibration of the structure has exceeded the limit based on the peak vibration velocity of the floor panel of the fifth layer. Therefore, it is necessary to combine numerical simulation results with field test results to reflect the dynamic response rule of the structure and accurately evaluate the vibration of the structure.

\section{Establishment and Verification of the Numerical Model}

4.1. Establishment of the Numerical Model. The dynamic characteristics of Liangxiang Pagoda are calculated by the finite element software ANSYS. According to the actual size of the structure, the bottom of the pagoda is fixed through solid modeling and an integral modeling method. The simulation is carried out with soild92 element. The element size is $0.5 \mathrm{~m}$, and the whole model contains 269,404 elements. For the accurate simulation of the pagoda, the stairs are modeled according to the actual size as well. Figure 11 shows the detailed numerical model diagram and the actual section diagram of Liangxiang Pagoda.

4.2. Modal Calibration. Due to the protection requirements of cultural relics, the mechanical properties of materials of Liangxiang Pagoda cannot be tested. Thus, with reference to the masonry materials of Jin'aozhou Pagoda [23], the mean density of Liangxiang Pagoda is $\rho=1765 \mathrm{~kg} / \mathrm{m}^{3}$, and Poisson's ratio is $\mu=0.15$. Meanwhile, the dynamic characteristics of the structure are calculated by adjusting the elasticity modulus repeatedly. The calculated results of natural vibration frequency under 5 typical operating modes are compared with the test results (see Table 4). The elasticity moduli of the 5 operating modes are as follows:

Operating mode 1: the elasticity modulus of the whole structure is $800 \mathrm{MPa}$

Operating mode 2 : the elasticity modulus of the whole structure is $700 \mathrm{MPa}$

Operating mode 3: the elasticity moduli from the foundation to the $2^{\text {nd }}$ floor are $700 \mathrm{MPa}$, and the elasticity moduli from the $3^{\text {rd }}$ to the $5^{\text {th }}$ floor and of the spire are $800 \mathrm{MPa}$

Operating mode 4: the elasticity moduli of the foundation and the $1^{\text {st }}$ floor are $900 \mathrm{MPa}$ and those of the $2^{\text {nd }}$ and $3^{\text {rd }}$ floor are $500 \mathrm{MPa}$; the elasticity moduli of the $4^{\text {th }}$ and $5^{\text {th }}$ floor are $550 \mathrm{MPa}$ and that of the spire is $1000 \mathrm{MPa}$ 


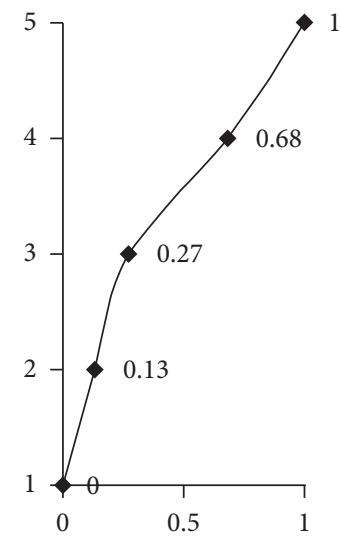

The 1st-order vibration mode

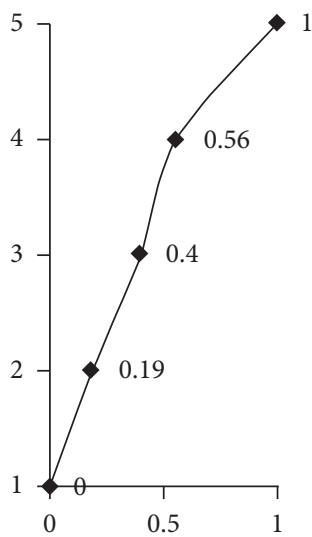

The 1st-order vibration mode

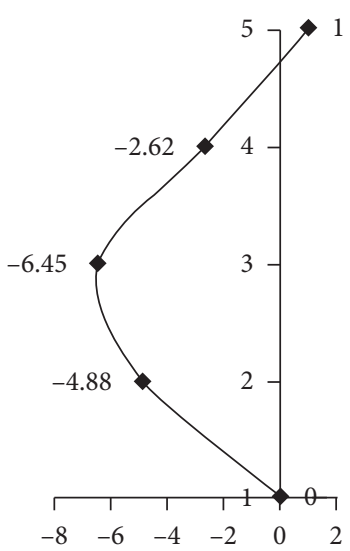

The 2nd-order vibration mode

(a)

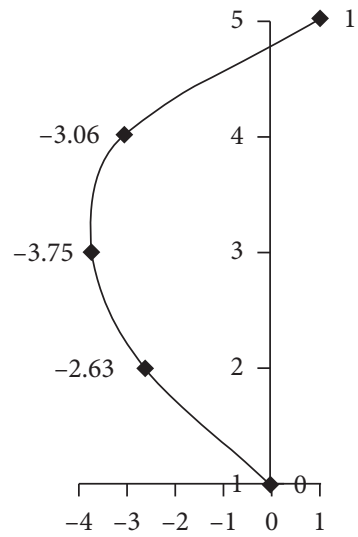

The 2nd-order vibration mode

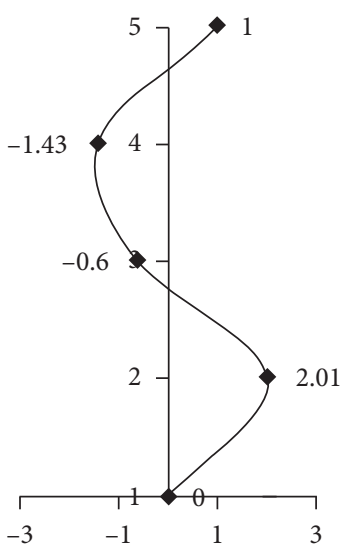

The 3rd-order vibration mode

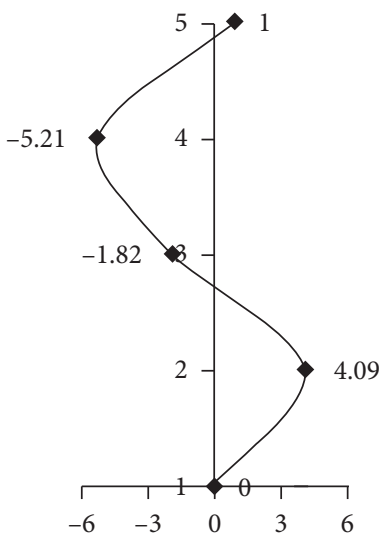

The 3rd-order vibration mode

(b)

Figure 9: Vibration mode diagrams of the first three orders. (a) East-west direction. (b) South-north direction.

TABLE 3: Test results of natural vibration frequency.

\begin{tabular}{lccc}
\hline $\begin{array}{l}\text { Type of } \\
\text { train }\end{array}$ & $\begin{array}{c}\text { Velocity of } \\
\text { train }(\mathrm{km} / \mathrm{s})\end{array}$ & $\begin{array}{c}\text { Passenger capacity/ } \\
\text { load capacity per } \\
\text { carriage }\end{array}$ & $\begin{array}{c}\text { The number } \\
\text { of trains }\end{array}$ \\
\hline $\begin{array}{l}\text { Direct } \\
\text { express }\end{array}$ & 160 & $36-118$ passengers & 2 \\
$\begin{array}{l}\text { Express } \\
\text { Fast }\end{array}$ & 140 & $46-118$ passengers & 5 \\
\hline
\end{tabular}

Operating mode 5: the elasticity moduli of the foundation and the $1^{\text {st }}$ floor are $950 \mathrm{MPa}$ and those of the $2^{\text {nd }}$ and $3^{\text {rd }}$ floor are $480 \mathrm{MPa}$; the elasticity moduli of the $4^{\text {th }}$ and $5^{\text {th }}$ floor are $500 \mathrm{MPa}$ and that of the spire is $950 \mathrm{MPa}$

As can be known from Table 2, the first three orders' frequencies under Operating Mode 5 are closer to the test ones. And the corresponding vibration modes calculated are shown in Figure 12. Only the vibration mode in the east-west direction is presented in Figure 12 because it does not differ significantly with that in the south-north direction. As shown in Figure 2, the calculated results agree well with the test ones, so the model is considered to be effective.

4.3. Excitation Input. Studies have shown that $[24,25]$ the calculation results of building vibration without considering the coupling of soil and structure are safer under the influence of environmental vibration [26-28]. The acceleration time history at P0 when the train passes by the testing site is used for model excitation; and the excitation lasts $30 \mathrm{~s}$ (see Figure 13). According to the uniform excitation method, the excitation is input at the bottom of the pagoda's numerical model. Research has shown that $[25,29,30]$ the results of the vibration response calculated with this method are safe. With Rayleigh damping, the damping coefficient is obtained by assigning the fundamental frequency of structure to $20 \mathrm{~Hz}$ and the damping ratio to 0.03 . Dynamic analysis is conducted by using the Newmark direct integration method, with an integral step of $0.00781 \mathrm{~s}$.

4.4. Dynamic Response Calibration. After the calculation is completed, the velocity responses at the measuring points of each floor are extracted to obtain the peak vibration 


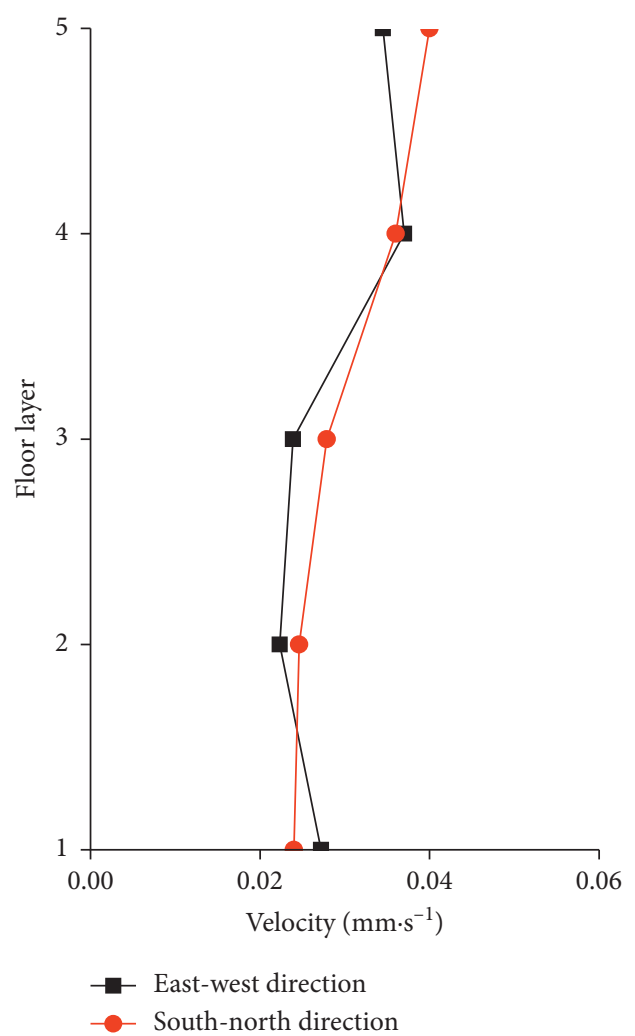

Figure 10: Peak velocity of each floor of Liangxiang Pagoda under the influence of trains.

velocities, which are then compared with the measured ones. The results show that they are in good agreement (see Figure 14).

In conclusion, the calculated results of the model can quantitatively reflect the actual vibration response of each floor of Liangxiang Pagoda when the train passes by.

\section{Calculation Results and Analysis}

5.1. Velocity Response Analysis of Liangxiang Pagoda. Under the influence of train, the time-history curve of Liangxiang Pagoda at the position that bears the maximum load (the roof panel of the fifth floor) is shown in Figure 15. It can be seen that the maximum vibration velocity in the east-west direction is $0.043 \mathrm{~mm} / \mathrm{s}$ and that in the southnorth direction is $0.053 \mathrm{~mm} / \mathrm{s}$.

Currently, all the domestic and foreign standards for allowable vibration of building structures take the peak vibration velocity as the vibration limit. The relevant vibration specifications are summarized in Table $5[1,31]$.

The "integrity" in Table 5 is concerning the damage degree of building; usually, it refers to the damage like surface cracking and peeling of the nonload-bearing components of ancient buildings caused by fatigue accumulation under microvibration; while the "safety" is concerning the damage degree of the structure, generally, it refers to the damage of the load-bearing components of ancient buildings that will endanger the safety of the structure under strong vibration (earthquake).
As can be known from Table 5, most foreign and domestic vibration standards on building structures are proposed for the safety of structures; the lower limit of PPV mainly ranges within $1.8 \sim 10 \mathrm{~mm} / \mathrm{s}$; that is, when vibration is below this limit, it usually does not cause structural damage.

The Technical Specifications for Protection of Historic Buildings against Man-Made Vibrations GBT50452-2008 is proposed for the integrity of the architecture. Because it was formulated based on the long-term effect of vibration after considering the safety and integrity of buildings, its requirements on microvibration are the strictest among similar international standards. It proposes to take the fatigue limit as the basis of vibration standard [36] and specifies the allowable vibration values according to the structural type, construction materials, and protection level of ancient buildings as well as the propagation velocity of elastic wave in the ancient building structure. It stipulates that the vibration limit for the ancient masonry structure of key historical and cultural sites under the state protection should range within $0.15 \sim 0.2 \mathrm{~mm} / \mathrm{s}$.

By comparing the peak vibration velocity of Liangxiang Pagoda under the influence of train-induced vibration with the vibration standard, it is found that the peak velocity of the position that bears the maximum load is $0.053 \mathrm{~mm} / \mathrm{s}$, which is much lower than $1.8 \mathrm{~mm} / \mathrm{s}$, the lower limit of vibration control for ancient buildings stipulated in domestic and foreign standards. Thus, a conclusion can be drawn that the structure of Liangxiang Pagoda is safe under train excitation. Besides, the peak velocity of the position that bears the maximum load is $0.053 \mathrm{~mm} / \mathrm{s}$, which is smaller than $0.15 \mathrm{~mm} / \mathrm{s}$, the lower limit proposed by the Technical Specifications for Protection of Historic Buildings against Man-Made Vibrations GB/T50452-2008.

5.2. Stress Analysis of Liangxiang Pagoda. The diagrams of the first and third main stresses under the action of gravity and train are shown in Figures 16 and 17.

The stress peaks under the action of gravity and train are listed in Table 6. It can be known from Table 6 that the compressive stress at the door hole in the inner wall of the first floor under gravity is the largest, which is far larger than the stress under trainload. Thus, it is believed that the maximum compressive stress under the joint action of gravity and train appears at this location, with a value of $1.39001977 \mathrm{MPa}$. That is to say, this position is the most dangerous place of the ancient pagoda. The fatigue life of the ancient pagoda will be calculated in Section 6 based on the compressive stress of this position.

\section{Fatigue Life Estimation of Liangxiang Pagoda}

There are two kinds of damage theories widely used currently at home and abroad, that is, linear cumulative fatigue damage theory and nonlinear fatigue cumulative damage theory. Yao [40] pointed out that when the excitation load of the structure is high-cycle fatigue, the linear theory completely meets the accurate needs of engineering. The linear theory has been widely applied due to its clear concept and 


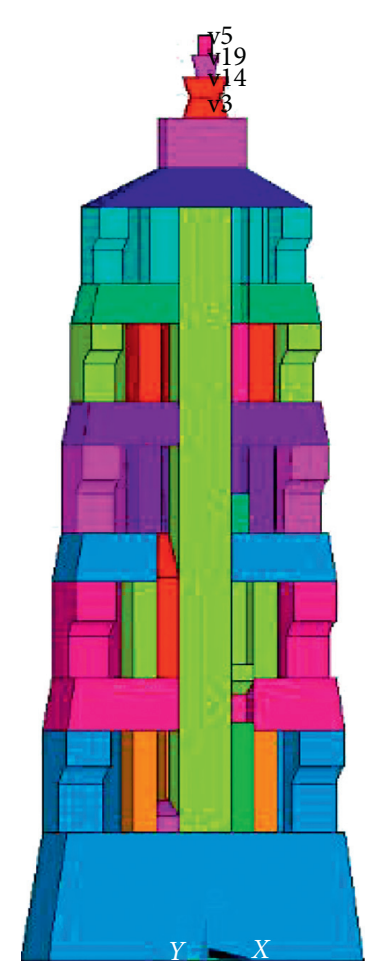

(a)

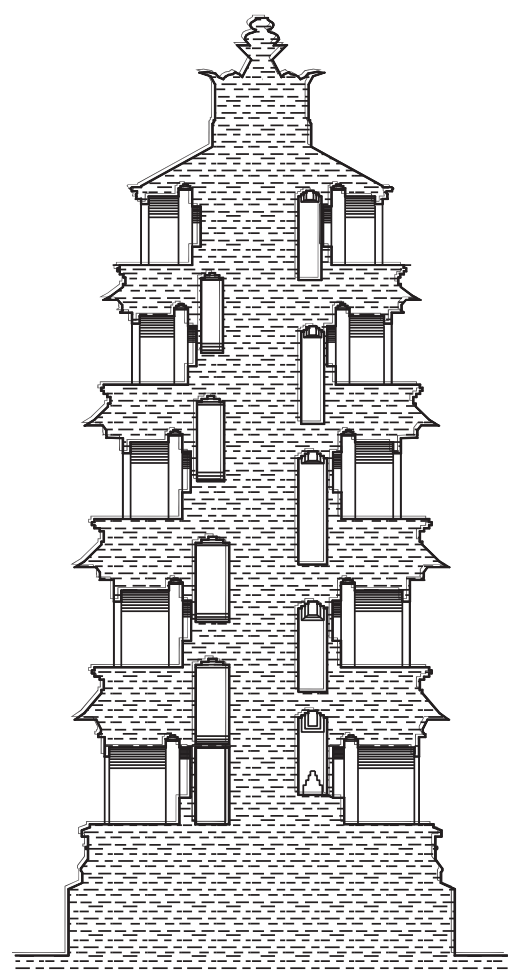

(b)

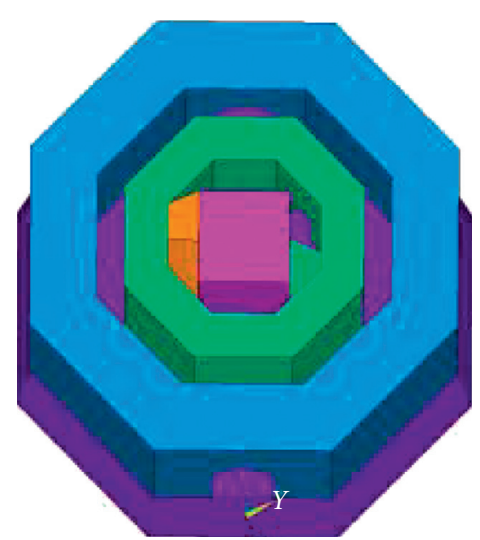

(c)

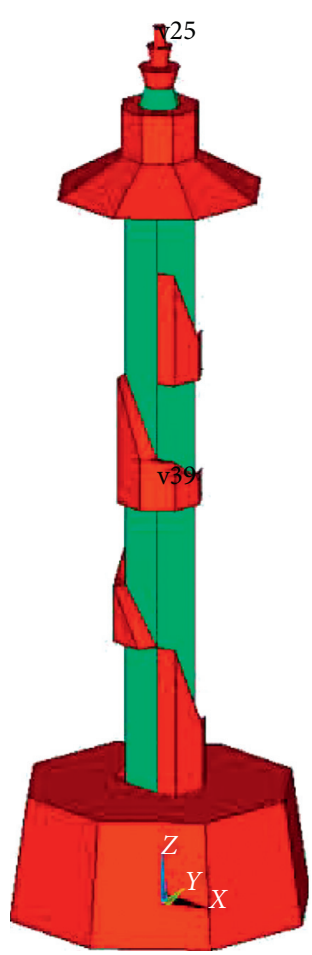

(d)

Figure 11: Numerical model diagram of Liangxiang Pagoda. (a) Section view by the numerical model. (b) Section view by surveying and mapping. (c) Plane. (d) Stairs.

simple calculation, while the nonlinear theory is often used in low-cycle fatigue. The number of train load cycles borne by the Liangxiang Pagoda is large, which belongs to the category of high-cycle fatigue. Therefore, this paper uses the linear fatigue cumulative damage theory to calculate and analyze the service life of Liangxiang Pagoda.

According to the theory [41], it is assumed that the fatigue life of the structure is $N$ under the long-term action of constant amplitude load $S$, and the damage caused by $N$ cycles is

$$
D=\frac{n}{N}
$$

When $D=0$, it indicates no damage has been caused to the structure; when $D=1$, it means that the structure suffers from fatigue failure.

Assuming that the structure, under the long-term action of variable-amplitude load $S_{i}$, suffers $n_{i}$ cycles of load under the action of $i$ stress loads, then the damage caused by each cycle is $\left(1 / N_{i}\right)$ and the damage caused by $n_{i}$ cycles is $D_{i}=\left(n_{i} / N_{i}\right)$, so the total damage is

$$
D=\frac{n_{1}}{N_{1}}+\frac{n_{2}}{N_{2}}+\cdots+\frac{n_{j}}{N_{j}}=\sum_{1}^{j} \frac{n_{i}}{N_{i}}, \quad i=1,2, \ldots, j .
$$

Fatigue failure occurs when $D=\sum_{1}^{j}\left(n_{i} / N_{i}\right)=1$.

On this basis, Qian et al. [42] performed a pressurepressure fatigue test on ancient masonry materials, through which the S-N curve of the ancient masonry is fitted:

$$
S=-0.30 \lg N+4.37
$$

where $S$ denotes the stress of structure and $N$ denotes the fatigue life of the pagoda.

6.1. Theoretical Calculation of the Fatigue Life of Liangxiang Pagoda. The time-history curve of the third main stress at the most dangerous position of the ancient pagoda under the influence of trains is shown in Figure 18. The multilevel load $S$ at the most dangerous position of the pagoda under the combined action of gravity and train is obtained by adding the stress in Figure 18 and the stress under gravity load. Based on equation (6), the fatigue life $N$ of each level load can be calculated according to $S$.

According to the linear fatigue theory, let the cycle times of each load level be $n$; then the fatigue life of pagoda under each load level can be calculated through equation (5). Let $\sum D=1$; there exists $1.90 \times 10^{-8} n=1$, the solution to which is $n=5.26 \times 10^{7}$.

6.2. Fatigue Life of Liangxiang Pagoda Calculated by Fe-Safe. First, inputting the dynamic response results in Fe-safe and defining the material parameters. Subsequently, the Miner theory is used to obtain the distribution diagram of the fatigue life of Liangxiang Pagoda under train action.

According to the calculation results of $\mathrm{Fe}$-safe, under the combined action of gravity and the train on the railway line that is $130 \mathrm{~m}$ away, the Liangxiang Pagoda has not been 
TABLE 4: Comparison of test results and calculated results of autopower frequency of Liangxiang Pagoda.

\begin{tabular}{|c|c|c|c|c|c|c|c|}
\hline \multicolumn{8}{|l|}{ Test results } \\
\hline Direction & & \multicolumn{2}{|c|}{ The $1^{\text {st }}$ order } & \multicolumn{2}{|c|}{ The $2^{\text {nd }}$ order } & \multicolumn{2}{|c|}{ The $3^{\text {rd }}$ order } \\
\hline East-west direction & & \multicolumn{2}{|c|}{1} & \multicolumn{2}{|c|}{3.25} & \multicolumn{2}{|c|}{6} \\
\hline South-north direction & & \multicolumn{2}{|l|}{1} & \multicolumn{2}{|l|}{3.25} & \multicolumn{2}{|l|}{5.875} \\
\hline $\begin{array}{l}\text { Calculated results } \\
\text { Direction }\end{array}$ & Operating mode & Calculated value & Deviation & Calculated value & Deviation & Calculated value & Deviation \\
\hline \multirow{5}{*}{ East-west direction } & 1 & 0.95 & -0.05 & 3.63 & 0.38 & 7.40 & 1.40 \\
\hline & 2 & 0.89 & -0.11 & 3.40 & 0.15 & 6.92 & 0.92 \\
\hline & 3 & 0.90 & -0.10 & 3.46 & 0.21 & 7.15 & 1.15 \\
\hline & 4 & 0.92 & -0.08 & 3.29 & 0.04 & 6.66 & 0.66 \\
\hline & 5 & 0.93 & -0.07 & 3.26 & 0.01 & 6.55 & 0.55 \\
\hline \multirow{5}{*}{ South-north direction } & 1 & 0.95 & -0.05 & 3.61 & 0.36 & 7.37 & 1.495 \\
\hline & 2 & 0.89 & -0.11 & 3.38 & 0.13 & 6.89 & 1.015 \\
\hline & 3 & 0.90 & -0.10 & 3.44 & 0.19 & 7.11 & 1.235 \\
\hline & 4 & 0.93 & -0.07 & 3.27 & 0.02 & 6.62 & 0.745 \\
\hline & 5 & 0.93 & -0.07 & 3.24 & -0.01 & 6.52 & 0.645 \\
\hline
\end{tabular}

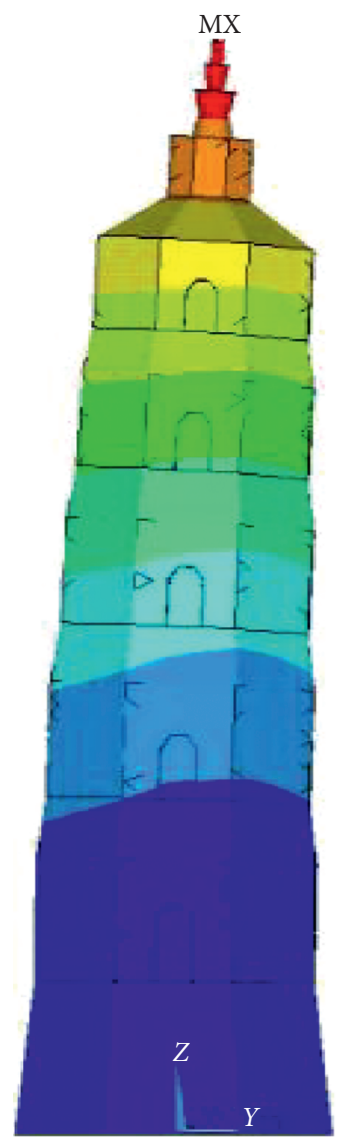

(a)

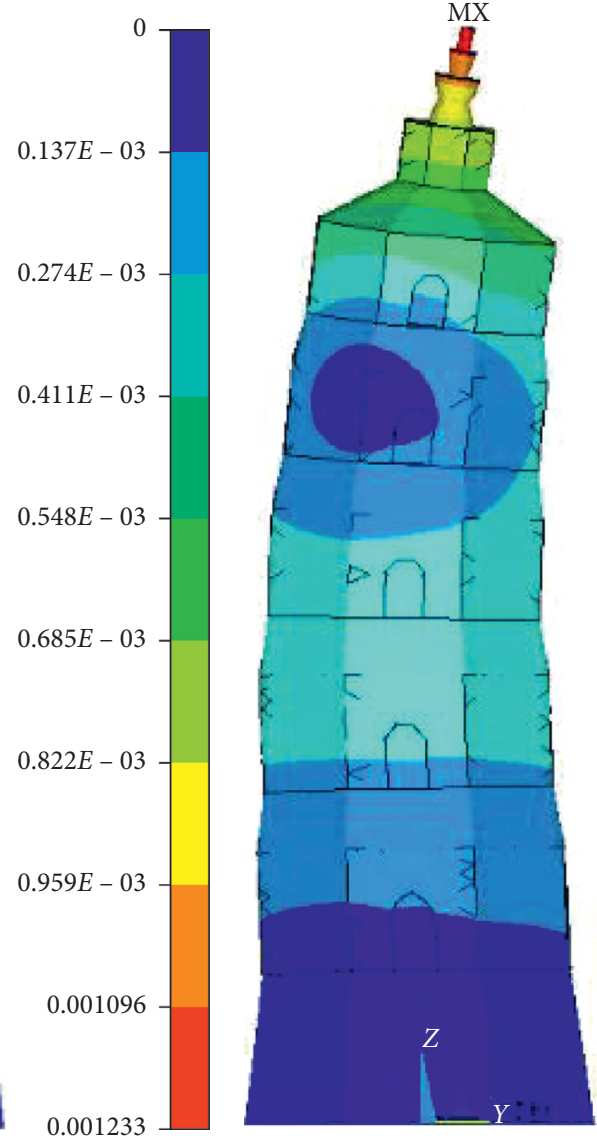

(b)

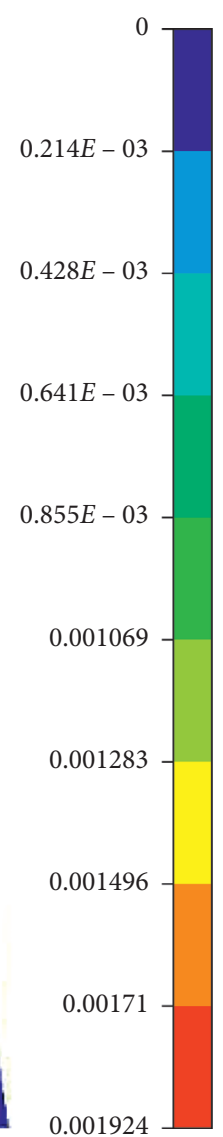

0.001924

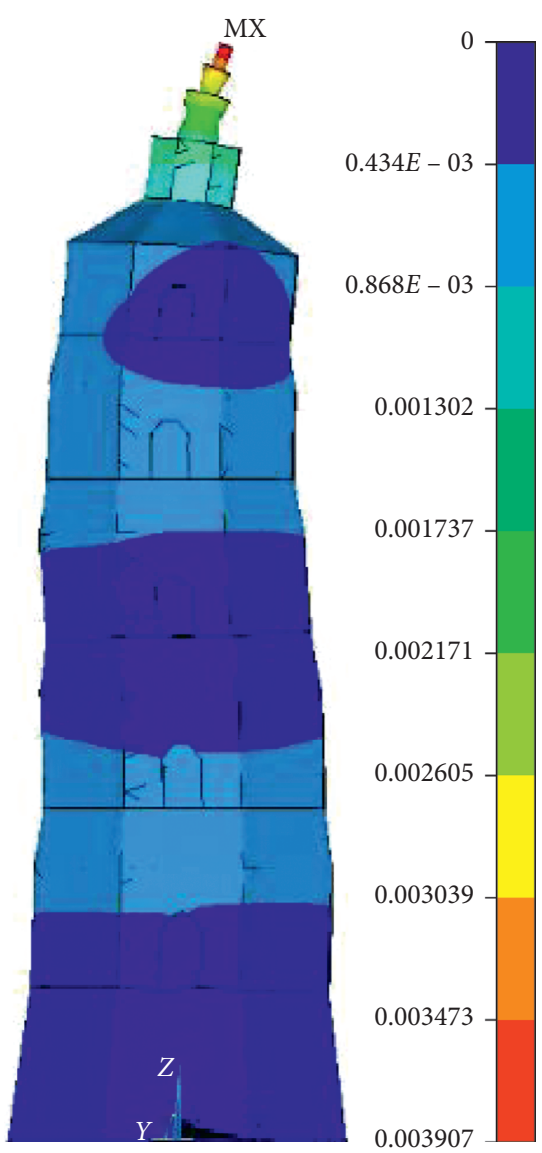

(c)

Figure 12: The vibration modes of Liangxiang Pagoda by calculation. (a) The $1^{\text {st }}$ order. (b) The $2^{\text {nd }}$ order. (c) The $3^{\text {rd }}$ order.

damaged by vibration fatigue, which is different from the theoretical calculation results. The main reason is that the theoretical calculation relies on stress to identify the most dangerous position; and for masonry structures under microvibration, its compressive stress is generally large and tensile stress is small, so the impact of tensile stress will be ignored in theoretical calculation, while the comprehensive influences of compressive stress and tensile stress are considered in Fe-safe calculation.

In order to identify the vulnerable positions of the ancient pagoda under microvibration excitation, the acceleration excitation at the ground of the pagoda is magnified by certain times to make the fatigue life calculated by Fe-safe more obvious. By referring to relevant studies [43], the 


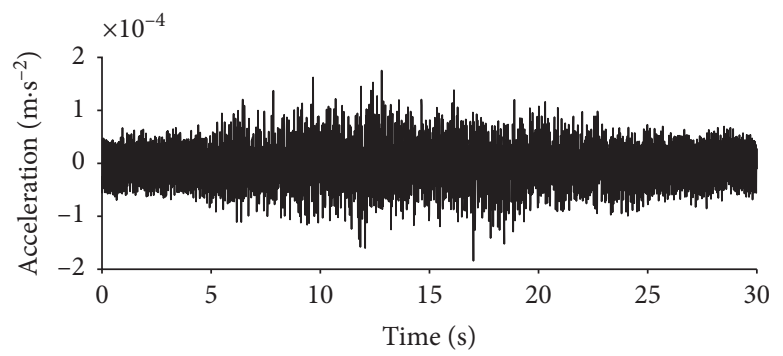

(a)

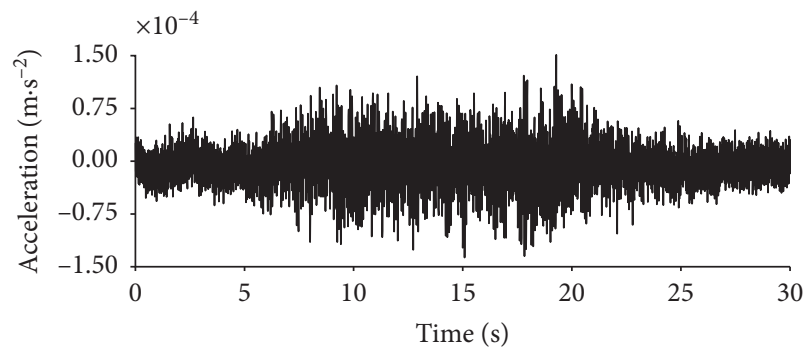

(b)

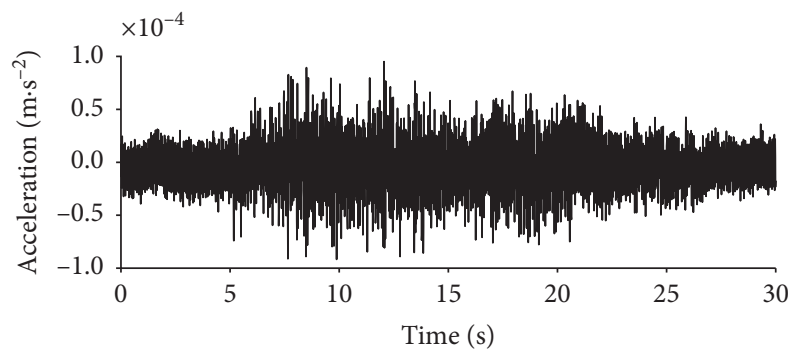

(c)

Figure 13: Acceleration-inputting time history. (a) Vertical direction. (b) Horizontal direction (south-north direction). (c) Horizontal direction (east-west direction).

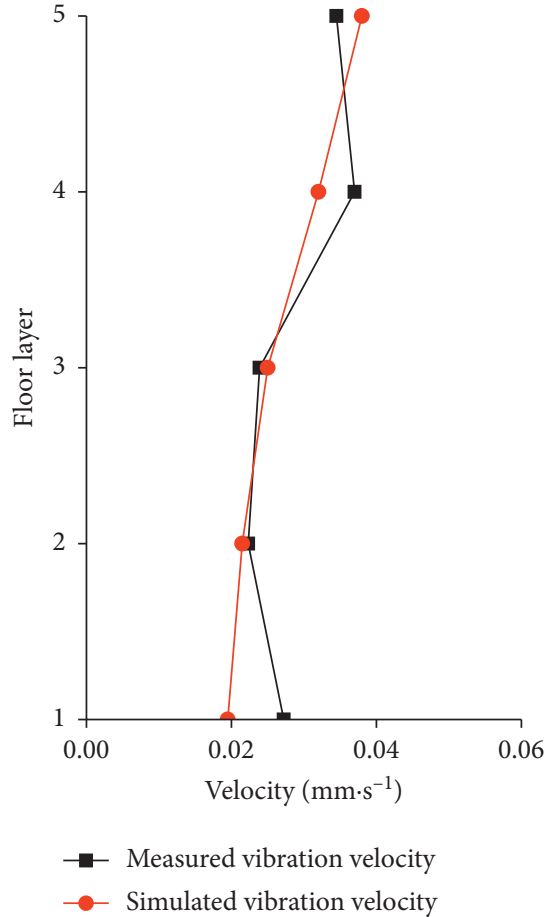

(a)

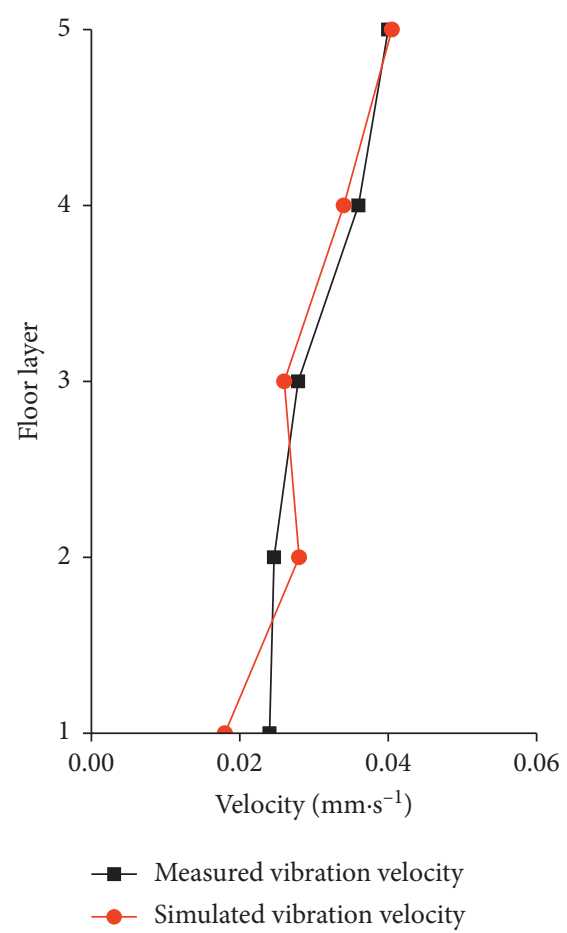

(b)

FIgURE 14: Comparison of calculated values and measured values. (a) East-west direction. (b) South-north direction.

horizontal acceleration at different distances from the railway line to the ground is obtained, as shown in Table 7.

As shown in Table 7, the measured acceleration at the ground of Liangxiang Pagoda was expanded by 30 times, 50 times, and 500 times, respectively, which are used as train excitation. Fe-safe is used to calculate the fatigue life of
Liangxiang Pagoda under the combined action of gravity and train. The overall distribution diagram of fatigue life (logarithm fatigue life) is shown in Figure 19. It should be pointed out that the results obtained by $\mathrm{Fe}$-safe are the times of the train-induced vibration the structure can withstand. Thus, the smaller the value in the fatigue life distribution 


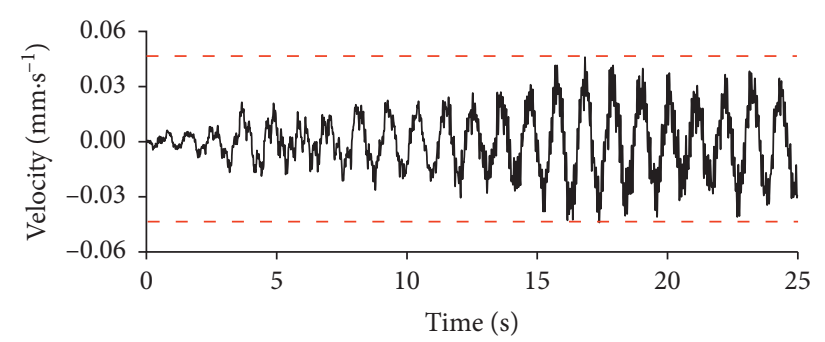

(a)

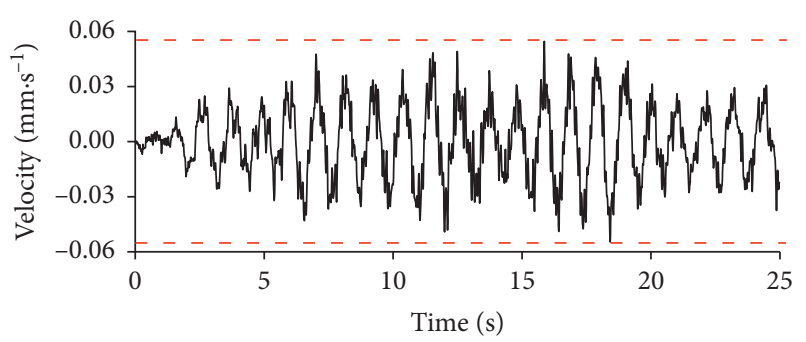

(b)

FIGURE 15: Time-history curves of velocity at the top of the $5^{\text {th }}$ floor of Liangxiang Pagoda under the impact of trains. (a) East-west direction. (b) South-north direction.

TABLE 5: Domestic and foreign control standards for ancient buildings.

\begin{tabular}{|c|c|c|c|}
\hline Names of standard or scholar & $\begin{array}{c}\text { Vibration } \\
\text { limit/(mm/s) }\end{array}$ & $\begin{array}{l}\text { Applicable } \\
\text { categories }\end{array}$ & Notes on applicability \\
\hline International standard ISO [32] & $2.5 \sim 10$ & Safety & \\
\hline German standard DIN4150-3-1999 [33] & 2.5 & Safety & $\begin{array}{l}\text { Long-term vibration; horizontal limiting value of the } \\
\text { top floor }\end{array}$ \\
\hline Swiss standard SN640312-1992 [34] & 3.0 & Safety & $\begin{array}{c}\text { The vibration sources are mechanical, transportation } \\
\text { and construction equipment }\end{array}$ \\
\hline FTA standard [35] & 3.08 & Safety & - \\
\hline $\begin{array}{l}\text { Technical specifications for protection of historic } \\
\text { buildings against man-made vibrations GB/ } \\
\text { T50452-2008 [36] }\end{array}$ & $0.15 \sim 0.2$ & Integrity & $\begin{array}{c}\text { The position that bears the maximum load (the key } \\
\text { cultural relics site under the state protection, ancient } \\
\text { masonry structure) }\end{array}$ \\
\hline Remington and Kurzweil [37] & 2 & Safety & - \\
\hline Konon and Schuring [38] & $6.4 \sim 12.7$ & Safety & - \\
\hline Yang and Pan [39] & 1.8 & Safety & - \\
\hline
\end{tabular}

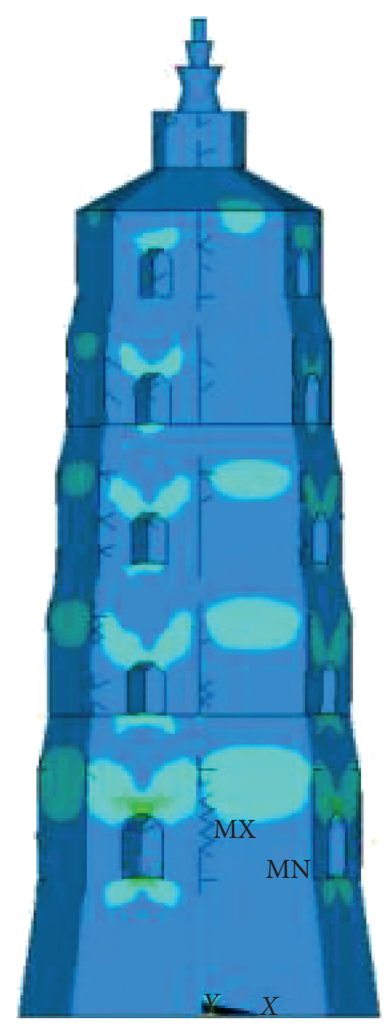

(a)

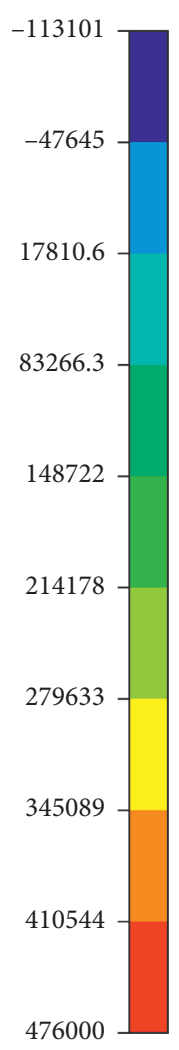

476000

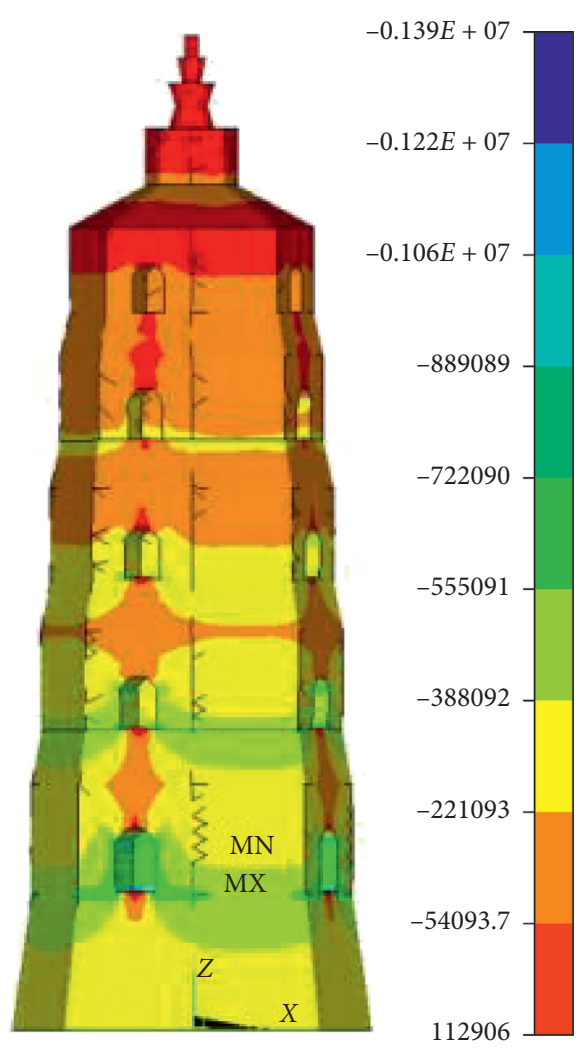

(b)

Figure 16: Stress diagrams of Liangxiang. (a) The first main stress. (b) The third main stress. 


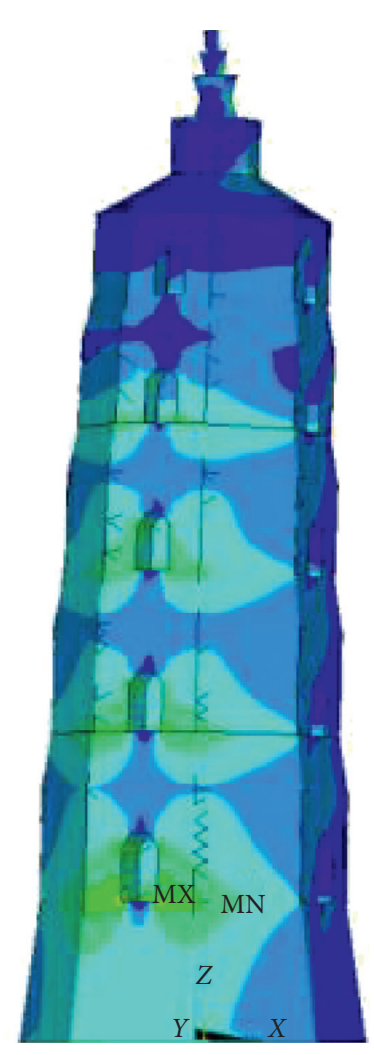

(a)

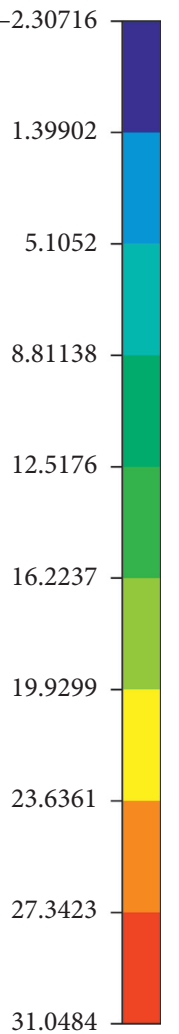

31.0484
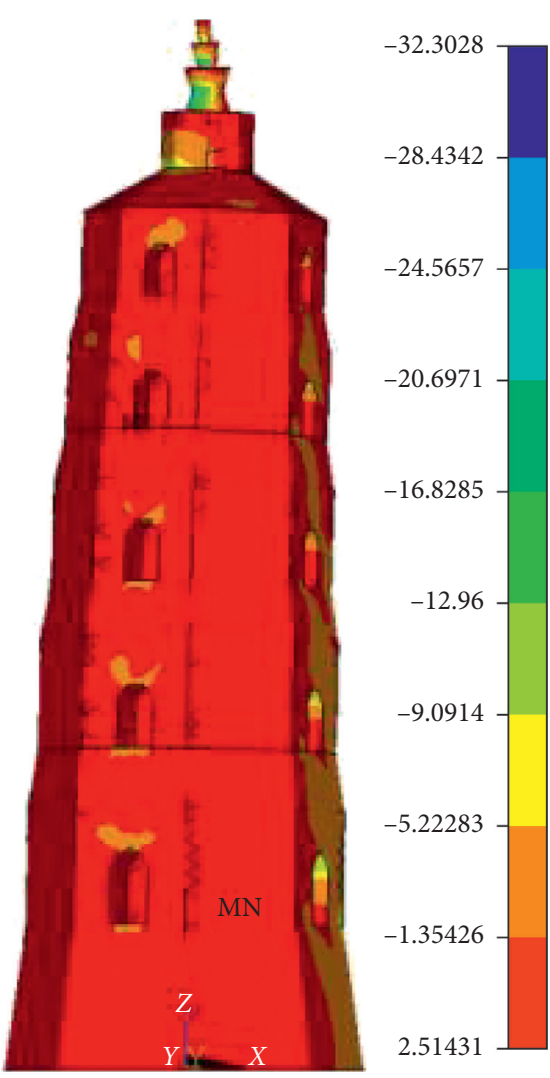

(b)

Figure 17: Stress diagrams of Liangxiang. (a) The first main stress. (b) The third main stress.

TABLE 6: Stress peaks under various loads.

\begin{tabular}{|c|c|c|c|c|}
\hline \multirow{2}{*}{ Load } & \multicolumn{2}{|c|}{ Maximum compressive stress } & \multicolumn{2}{|c|}{ Maximum tensile stress } \\
\hline & Stress $(\mathrm{MPa})$ & Location & Stress $(\mathrm{MPa})$ & Location \\
\hline Gravity & 1.39 & $\begin{array}{l}\text { The top of the door hole in the } \\
\text { inner wall of the } 1^{\text {st }} \text { floor }\end{array}$ & 0.476 & $\begin{array}{l}\text { The solid column at } \\
\text { the center of the } 1^{\text {st }} \text { floor }\end{array}$ \\
\hline Train & $3.23 \times 10^{-5}$ & Foundation & $3.10 \times 10^{-5}$ & $\begin{array}{l}\text { The bottom the door hole in } \\
\text { the inner wall of the } 1^{\text {st }} \text { floor }\end{array}$ \\
\hline
\end{tabular}

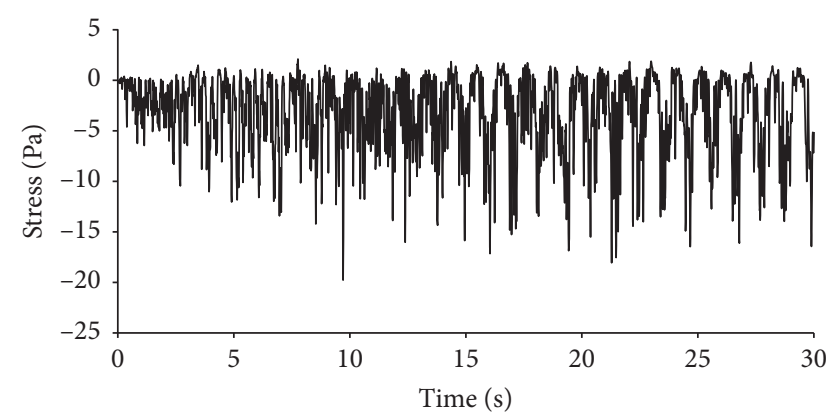

FIGURE 18: The time-history curve of the third main stress at the most dangerous position of the ancient pagoda.

diagram, the more dangerous the structure; the higher the value, the safer the structure.

Figure 19 shows that the closer it is to the railway line, the greater the fatigue damage of Liangxiang Pagoda; the lower the floor, the shorter the fatigue life of the pagoda of the corresponding floor; the fatigue lives of the structural floor levels are shorter than those of the upper and lower half walls; the fatigue lives of the upper and lower half walls of door and window are longer than those of their right and left sides. To better understand the fatigue life distribution of various positions of the ancient pagoda, the fatigue life distribution of the floors in Figure 19 is extracted, as shown in Figure 20. Due to space limitation, only Figure 19(a) is taken as an example for analysis. It can be seen from Figure 20 that the fatigue lives of the floor areas where windows, doors, and corridors are located are longer.

The results of the first and third main stresses of each floor under the combined action of gravity and train calculated in Section 5 are extracted and the corresponding diagrams are shown in Figures 21 and 22. It can be known that, under the combined action of gravity and train, tensile stress is mainly applied to the floor areas where doors, 
TABLE 7: The horizontal acceleration at different distances from the railway line to the ground $\left(\mathrm{m} / \mathrm{s}^{2}\right)$.

\begin{tabular}{lcc}
\hline Distance to railway line & Acceleration at the ground $a_{x}$ & The excitation of this paper being magnified by $X$ times \\
\hline $10 \mathrm{~m}$ & $5 \times 10^{-2}$ & 500 times \\
$30 \mathrm{~m}$ & $5 \times 10^{-3}$ & 50 times \\
$40 \mathrm{~m}$ & $3 \times 10^{-3}$ & 30 times \\
This paper $130 \mathrm{~m}$ & $1 \times 10^{-4}$ & \\
\hline
\end{tabular}

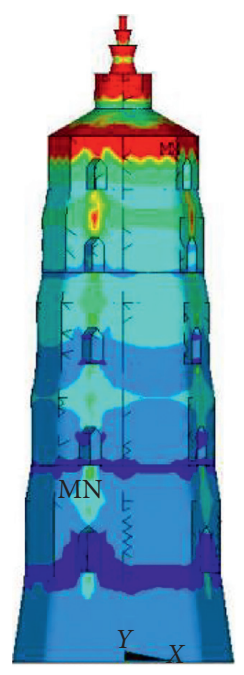

(a)

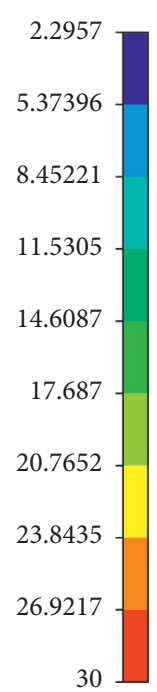

30

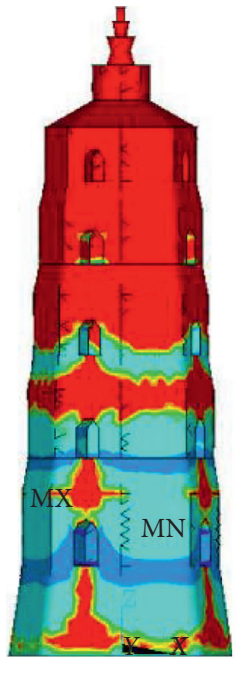

(b)

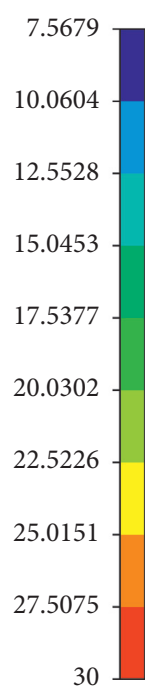

30

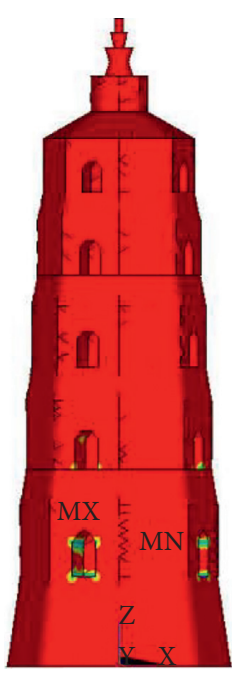

(c)

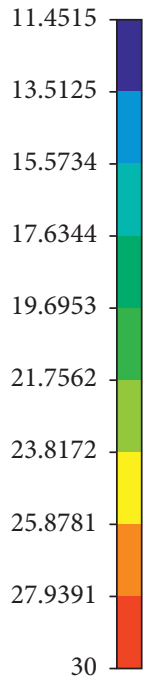

Figure 19: Distribution diagrams of fatigue life of Liangxiang Pagoda (lgN). (a) $10 \mathrm{~m}$ away from the railway line. (b) $30 \mathrm{~m}$ away from the railway line. (c) $40 \mathrm{~m}$ away from the railway line.

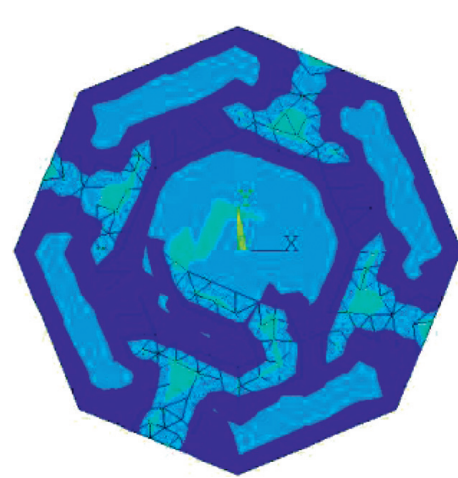

(a)

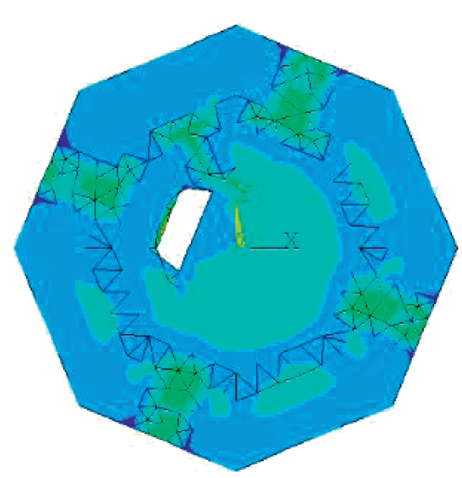

(c)
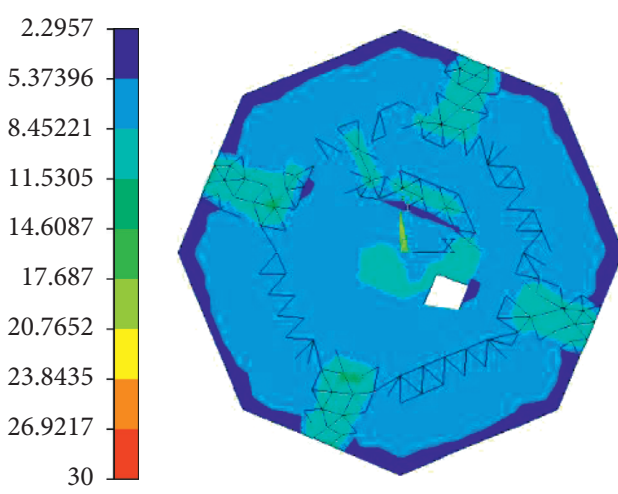

(b)
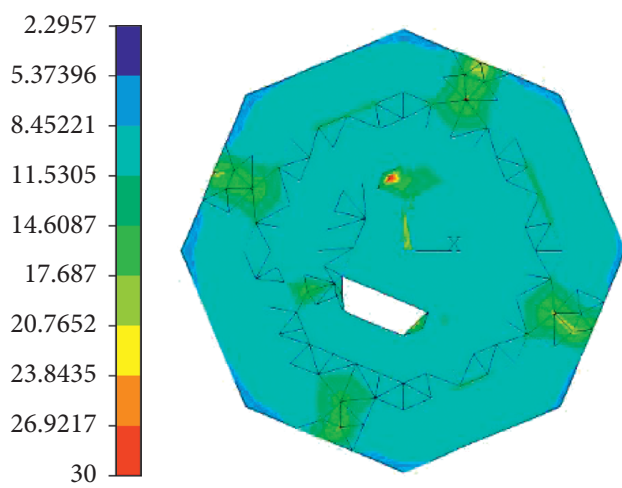

(d)
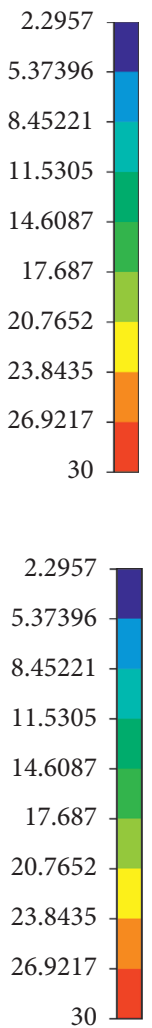

30

Figure 20: Continued. 

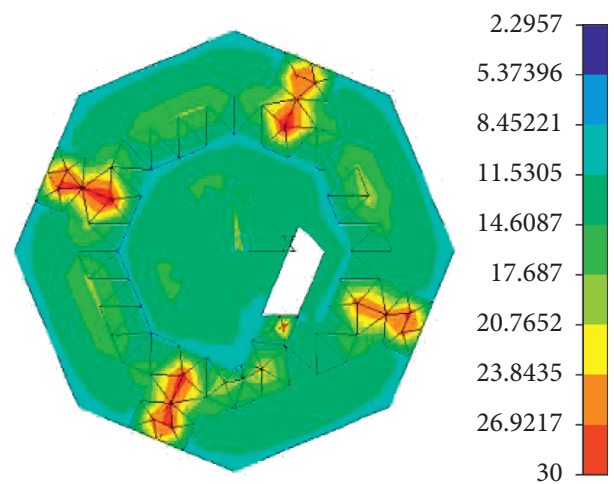

(e)

Figure 20: Distribution diagrams of fatigue life Liangxiang Pagoda at each floor (lgN). (a) Top view of the first floor. (b) Top view of the second floor. (c) Top view of the third floor. (d) Top view of the fourth floor. (e) Top view of the fifth floor.

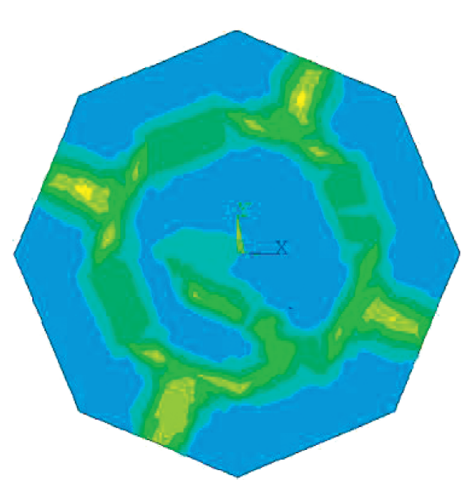

(a)

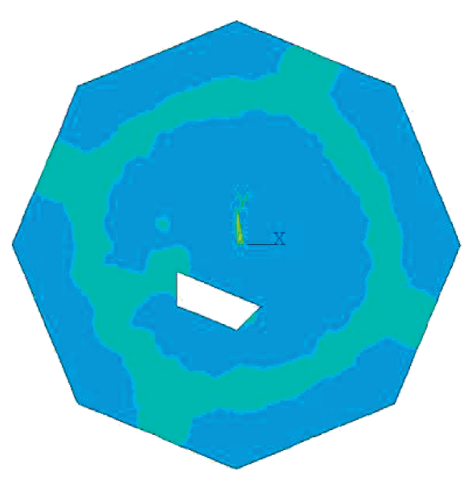

(c)
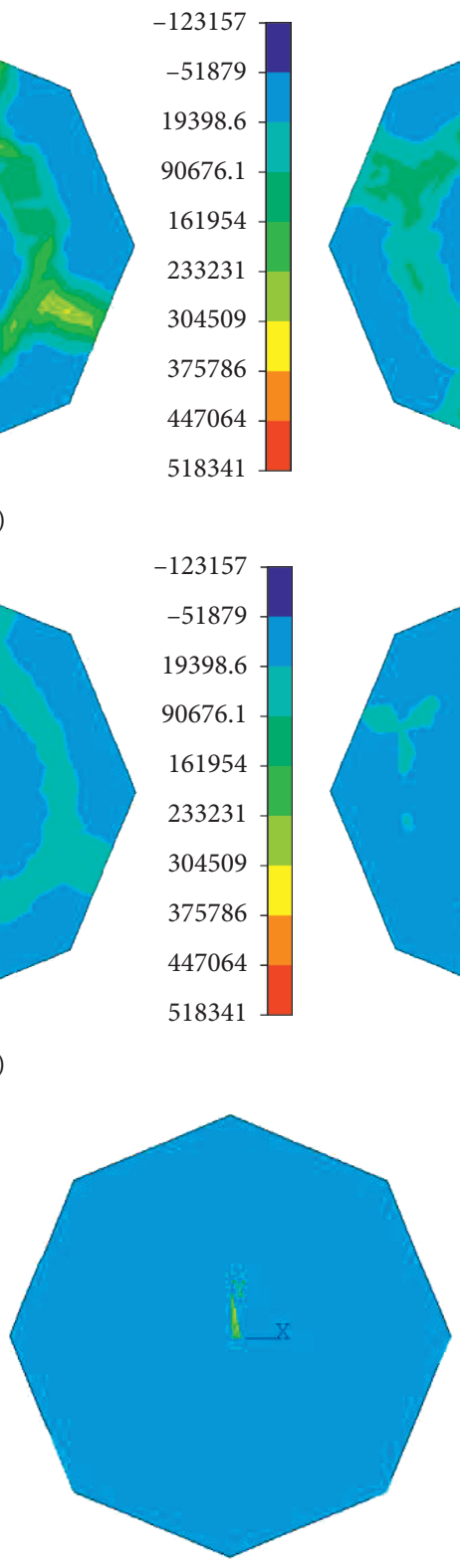

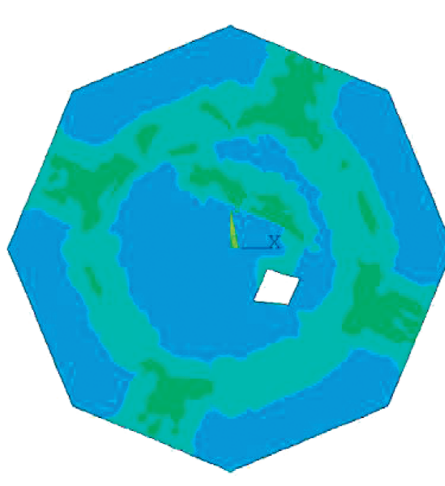

(b)

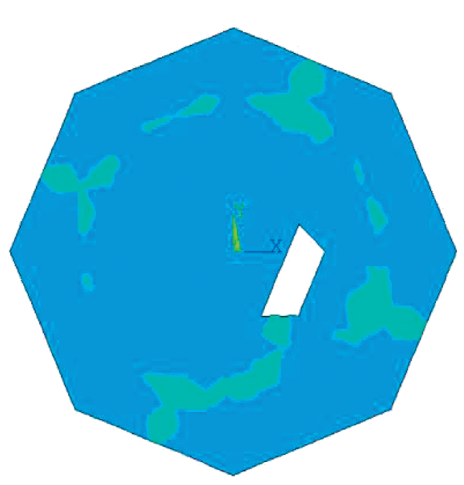

(d)

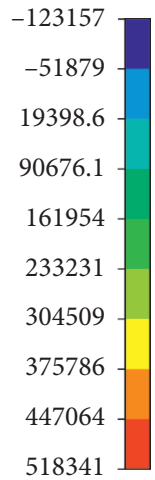

-123157
-51879
19398.6
90676.1
161954
233231
304509
375786
447064
518341

$$
\begin{array}{r}
-123157 \\
-51879 \\
19398.6 \\
90676.1 \\
161954 \\
233231 \\
304509 \\
375786 \\
447064 \\
518341
\end{array}
$$

(e)

Figure 21: The first main stress diagram of each floor under the combined action of gravity and train (MPa). (a) Top view of the first floor. (b) Top view of the second floor. (c) Top view of the third floor. (d) Top view of the fourth floor. (e) Top view of the fifth floor. 


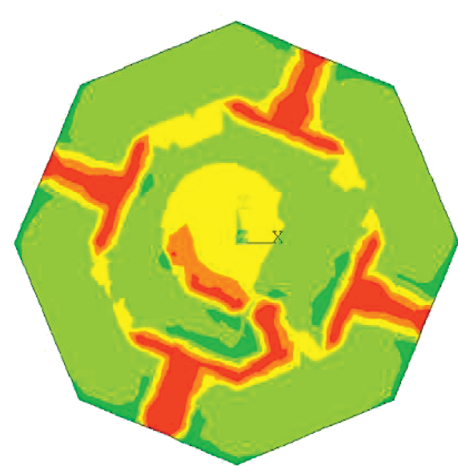

(a)

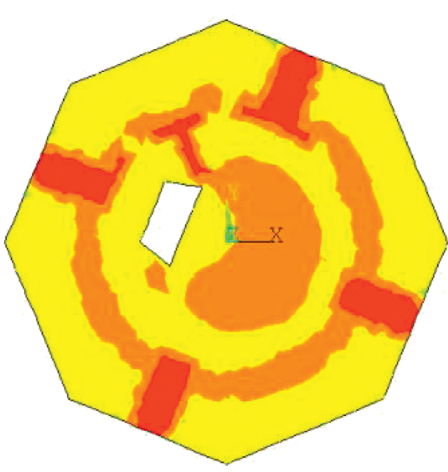

(c)

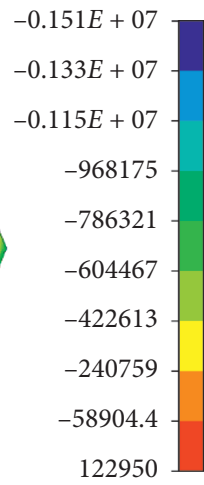

122950

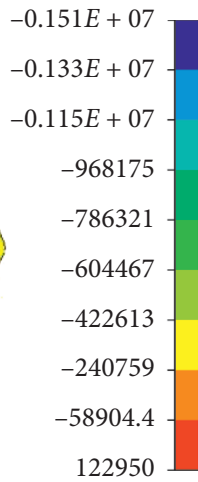

22950

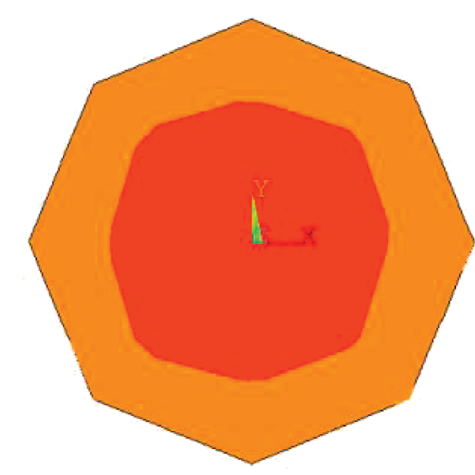

(e)

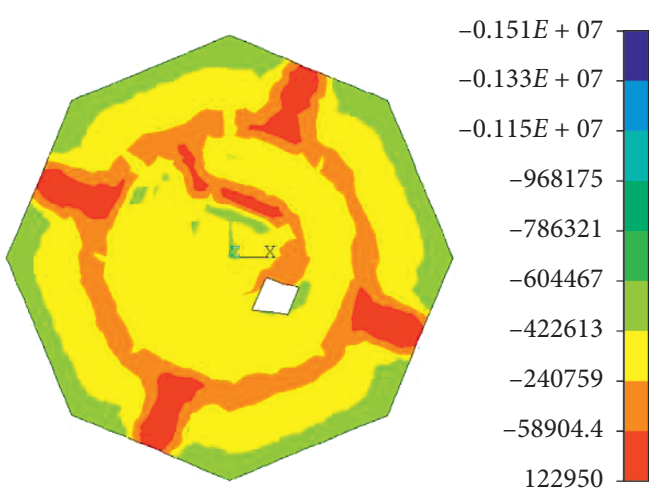

(b)

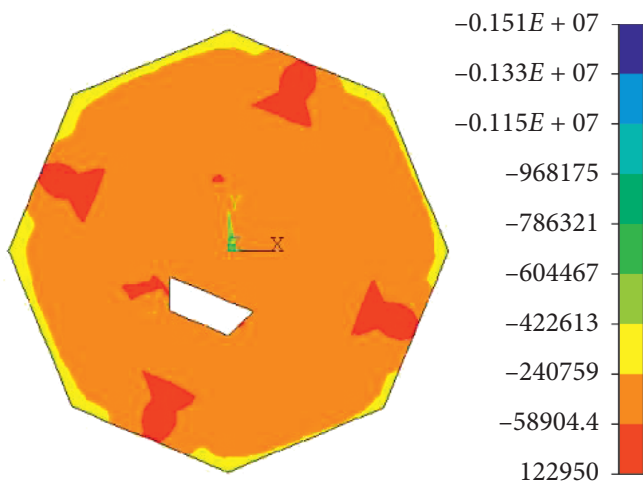

(d)

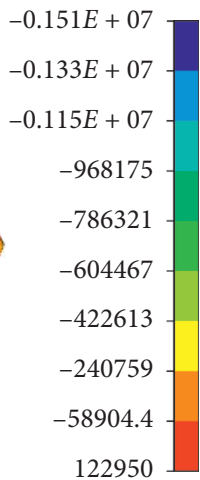

122950

Figure 22: The third main stress diagram of each floor under the combined action of gravity and train (MPa). (a) Top view of the first floor. (b) Top view of the second floor. (c) Top view of the third floor. (d) Top view of the fourth floor. (e) Top view of the fifth floor.

windows, and corridors are located. By comparing the fatigue life diagram with the stress diagram, it can be found that the tensile stress at the floor areas where doors, windows, and corridors are located that is generated by the combined action of gravity and train has a favorable effect on the fatigue life of ancient buildings with existing damage.

\section{Conclusions}

(1) The natural vibration frequencies of Liangxiang Pagoda of the first three orders in the east-west direction are $1 \mathrm{~Hz}, 3.25 \mathrm{~Hz}$, and $6 \mathrm{~Hz}$, and those in the south-north direction are $1 \mathrm{~Hz}, 3.25 \mathrm{~Hz}$, and
$5.875 \mathrm{~Hz}$. The vibration mode curves in the east-west direction and south-north direction are the same; specifically, the $1^{\text {st }}$ order vibration modes in the plane are bending, and vibration modes of the $2^{\text {nd }}$ and $3^{\text {rd }}$ orders are shear-bending.

(2) Under the excitation of trains, the vibration velocities of the floors of Liangxiang Pagoda in the east-west and south-north directions present different rules with the increase of floor layers; specifically, the peak velocity in the east-west direction is more complex; that is, it shows a large change in the fourth floor and a slightly decreasing-increasing-decreasing tend from the first floor to the top floor while the vibration velocity in the south- 
north direction is relatively regular and shows a slowgrowing trend in general.

(3) Under the influence of trains, the peak vibration value of Liangxiang Pagoda at the position that bears the maximum load is $0.053 \mathrm{~mm} / \mathrm{s}$, which has a little impact on the safety and integrity of the pagoda.

(4) Under the combined action of gravity and trains, the remaining fatigue life of Liangxiang Pagoda is $5.26 \times$ $10^{7}$ times. The lower the floor, the shorter the fatigue life of the ancient pagoda at the corresponding floor; the fatigue lives of the structural floor levels are shorter than those of the upper and lower half walls; the fatigue lives of the upper and lower half walls of door and window are longer than those of their right and left sides; the fatigue lives of floor areas where windows, doors, and corridors are located are longer than those of other areas.

(5) This paper proposes for the first time to study ancient architectures from the perspective of fatigue life and by combining theoretical calculation with fatigue analysis software Fe-safe to analyze the fatigue life of ancient masonry architectures scientifically and systematically. The method proposed in this paper can provide data and scientific supports for the protection of historical architectures, as well as a data basis for the follow-up research of the studied ancient pagoda.

\section{Data Availability}

The data used to support the findings of this study are available from the corresponding author upon request.

\section{Conflicts of Interest}

The authors declare that they have no conflicts of interest.

\section{Acknowledgments}

This work was supported by the National Natural Science Fund (51708450); China Postdoctoral Science Foundation Project (2018M643702); Basic Research Project of Natural Science in Shaanxi Province (2018JQ5169); Shaanxi Provincial Postdoctoral Foundation Project (2018BSHEDZZ22); Ph.D. Research Start-Up Project (107451115002); and School-Level Scientific Research Project (2016CX025).

\section{References}

[1] Q. Xia, J. Zhao, M. Ma et al., "Research status of the influence of traffic vibration on damage mechanism and fatigue life of masonry ancient buildings," Noise and Vibration Control, vol. 38, no. 6, pp. 135-212, 2018.

[2] J. Zhao, Study on Fatigue Life of Ancient Masonry Pagoda under Train Vibration, Xi'an University of Technology, Xi'an, China, 2019.
[3] K.-G. Hinzen, "Subway-induced vibrations in Cologne Cathedral," Seismological Research Letters, vol. 85, no. 3, pp. 631-638, 2014.

[4] L. Schillemans, "Impact of sound and vibration of the northsouth high-speed railway connection through the city of Antwerp Belgium," Journal of Sound and Vibration, vol. 267, no. 3, pp. 637-649, 2003.

[5] J. Sadeghi and M. H. Esmaeili, "Safe distance of cultural and historical buildings from subway lines," Soil Dynamics and Earthquake Engineering, vol. 96, pp. 89-103, 2017.

[6] Z. B. Meng, Analysis and Assessment of the Vibration Responds Traffic-Induced of Xi'an Bell Tower, Xi'an University of Architecture \& Technology, Xi'an, China, 2009.

[7] Z. B. Meng, J. Yuan, and M. Z. Wu, "Experiment investigation of micro-vibration in wooden structure of Xi'an bell tower caused by traffic vehicles," Journal of Xi'an University of Architecture \& Technology (Natural Science Edition), vol. 41, no. 4, pp. 512-517, 2009.

[8] M. Ma, W. Liu, C. Qian, G. Deng, and Y. Li, "Study of the train-induced vibration impact on a historic bell tower above two spatially overlapping metro lines," Soil Dynamics and Earthquake Engineering, vol. 81, pp. 58-74, 2016.

[9] M. Ma, W. N. Liu, and D. Y. Ding, "Influence of metro traininduced vibration on Xi'an bell tower," Journal of Beijing Jiaotong University, vol. 34, no. 4, pp. 88-92, 2010.

[10] Z. Y. Yun, Study of Urban Transport Track Vibration Impact on the Brick Pagoda, Xi'an University of Architecture \& Technology, Xi'an, China, 2014.

[11] E. Poveda, R. C. Yu, J. C. Lancha, and G. Ruiz, “A numerical study on the fatigue life design of concrete slabs for railway tracks," Engineering Structures, vol. 100, no. 10, pp. 455-467, 2015.

[12] M. Tarifa, X. Zhang, G. Ruiz, and E. Poveda, "Full-scale fatigue tests of precast reinforced concrete slabs for railway tracks," Engineering Structures, vol. 100, no. 10, pp. 610-621, 2015.

[13] Z. P. Zeng, X. S. Wang, and W. R. Chen, "Study on fatigue characteristic of double block ballastless track under coupling loads," Advanced Materials Research, vol. 422, pp. 789-793, 2012.

[14] Z. L. Li and Y. Xing, "Fatigue behavior analysis and life prediction of main bridge of Xixi river bridge," Journal of Hebei Engineering and Technical College, vol. 3, pp. 36-41, 2017.

[15] L. M. Peng, C. H. Shi, J. Huang et al., "Study on the fatigue life of the tunnel bed structure under train loads," Journal of the China Railway Society, vol. 29, no. 1, pp. 82-85, 2007.

[16] W. G. Yan, Research on Dynamic Response and Fatigue Life in Bottom Structure of Heavy Haul Railway Tunnel, Central South University, Changsha, China, 2014.

[17] J. Wang, Application of MATLAB in Vibration Signal Processing, China Water \& Power Press, Beijing, China, 2006.

[18] Y. X. Jia, M. Guo, W. N. Liu et al., "Dynamic effect of traininduced vibration on historic buildings," Journal of Beijing Jiaotong University, vol. 33, no. 1, pp. 118-122, 2009.

[19] K. F. Li, W. N. Liu, W. F. Liu et al., "Tests and analysis of traffic-induced vibration effects on surrounding historic buildings," Journal of Beijing Jiaotong University, vol. 35, no. 1, pp. 79-83, 2011.

[20] H. Q. Ying, Waveform and Spectrum Analysis and Random Data Processing, China Railway Publishing House, Beijing, China, 1985.

[21] G. Q. Li and J. Li, Theory and Application of Dynamic Detection of Engineering Structure, Science Publishing House, Beijing, China, 2002. 
[22] J. B. Liu and X. L. Du, Dynamics of Structures, China Machine Press, Beijing, China, 2005.

[23] T. C. Chen, H. Deng, and X. H. Luo, "Dynamic characteristics analysis and test for Jin'aozhou Pagoda," Journal of Vibration and Shock, vol. 29, no. 4, pp. 193-196, 2010.

[24] T. Y. Wang, Study on Environmental Vibration Caused by Metro and Vibration Isolation Method of Buildings, Tongji University, Shanghai, China, 2008.

[25] Q. Xia and W. J. Qu, "Experimental and numerical studies of metro train-induced vibrations on adjacent masonry buildings," International Journal of Structural Stability and Dynamics, vol. 16, no. 10, 2016.

[26] M. Hyodo, Y. Wu, N. Aramaki, and Y. Nakata, "Undrained monotonic and cyclic shear response and particle crushing of silica sand at low and high pressures," Canadian Geotechnical Journal, vol. 54, no. 2, pp. 207-218, 2017.

[27] X. Wang, J. Cui, Y. Wu, C. Zhu, and X. Z. Wang, "Mechanical properties of calcareous silts in a hydraulic fill island-reef," Marine Georesources \& Geotechnology, pp. 1-14, 2020.

[28] Y. Wu, H. Yamamoto, J. Cui, and H. Cheng, "Influence of load mode on particle crushing characteristics of silica sand at high stresses," International Journal of Geomechanics, vol. 20, no. 3, 2020.

[29] K. H. Chua, K. W. Lo, and T. Balendra, "Building response due to subway train traffic," Journal of Geotechnical Engineering, vol. 121, no. 11, pp. 747-754, 1995.

[30] T. Hanazato, K. Ugai, M. Mori, and R. Sakaguchi, "Threedimensional analysis of traffic-induced ground vibrations," Journal of Geotechnical Engineering, vol. 117, no. 8, pp. 1133-1151, 1991.

[31] Q. Xia, J. Zhao, D. F. Wang et al., "Research on vibration law of ancient pagoda in Liao dynasty based on dynamic characteristic analysis under train excitation," Building Structure, vol. 49, no. 14, pp. 124-130, 2019.

[32] Professional Committee of Building Vibration of China Engineering Construction Standardization Association, Manual of Building Vibration Engineering, China Construction Industry Publishing House, Beijing, China, 2002.

[33] Deutsch Institut fur Normung, DIN4150-3 Structure Vibration Part 3: Effects of Vibration Onstructure, Deutsch Institut fur Normung, Berlin, Germany, 1999.

[34] H. G. Zhang, W. N. Liu, W. F. Liu et al., "Study on standard for assessing effects on structures of metro line 2 due to vibrations induced by underground trains on diameter line in Beijing," Tunnel Construction, vol. 27, no. S2, pp. 93-97, 2007.

[35] Office of Planning and Environment and Federal Transit Administration US, FTA-VA-90-91003-06 Transit Noise and Vibration Impact Assessment, Federal Transit Administration US, Washington, DC, USA, 2006.

[36] Ministry of Housing and Urban-Rural Development of the People's Republic of China, General Administration of Quality Supervision, and Inspection and Quarantine of the People's Republic of China, Technical Specifications for Protection of Historic Buildings against Man-Made Vibration (GB/T 50452-2008), China Architecture \& Building Press, Beijing, China, 2008.

[37] P. J. Remington and L. G. Kurzweil, Low-Frequency Noise and Vibrations from Trains, Nelson P M. Transportation Noise, Butterworth \& Co. Ltd., London, UK, 1987.

[38] W. Konon and J. Schuring, "Vibration criteria for historic buildings," Journal of Construction Engineering and Management, vol. 111, no. 3, pp. 209-215, 1985.

[39] X. J. Yang and F. L. Pan, "Anti-vibration protection of ancient buildings in environmental vibration," in Proceedings of the 7th Symposium on Soil Mechanics and Foundation Engineering of the Chinese Society of Civil Engineering, Xi'an, China, 1994.

[40] W. X. Yao, Fatigue Life Prediction of Structures, National Defense Industry Press, Beijing, China, 2003.

[41] X. H. Yang, W. X. Yao, and C. M. Duan, "The review of ascertainable fatigue cumulative damage rule," Engineering Science, vol. 5, no. 4, pp. 81-87, 2003.

[42] C. Y. Qian, J. G. Zheng, Y. Zhang et al., "Study on industrial vibration control standard for platform of Xi'an bell tower," Building Structure, vol. 45, no. 19, pp. 26-31, 2015.

[43] H. Xia, Traffic Induced Environmental Vibrations and Controls, Science Publishing House, Beijing, China, 2010. 